Telma de Barros Correia

Khaled Ghoubar

Yvonne Mautner

\section{BRASIL, SUAS FÁBRICAS $e$ VILAS OPERÁRIAS}

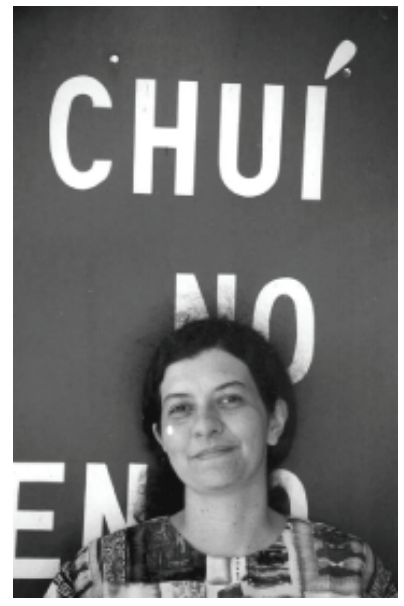

Philip Gunn e Telma de Barros Correia durante a pesquisa, em Chuí, Rio Grande do Sul, em 1997 Fotos: Telma de Barros Correia; Philip Gunn

O lançamento, em São Paulo, do volume 7, n. 1 da Revista Brasileira de Estudos Urbanos e Regionais da ANPUR, foi realizado na FAU por sugestão de Henri Acselrad (UFRJ - editor da revista) e de Maria Flora Gonçalves (Unicamp - membro da comissão editorial da revista). O interesse especial se dirigia ao último artigo de Philip Gunn (FAUUSP), em colaboração com Telma de Barros Correa (EESC/USP), que aborda o trabalho histórico sobre o estado atual da espacialização dos estabelecimentos industriais Brasil afora, projeto de pesquisa no qual ambos estiveram envolvidos nos últimos dez anos.

Para participar dessa homenagem da ANPUR ao Phil, propusemo-nos na FAU a completá-la na forma de uma pequena amostra do imenso e significativo acervo de fotos recolhido durante todos esses anos de pesquisa, métier no qual Phil era mestre.

Na página de abertura da exposição foi ainda acrescentada uma homenagem de Jonathan Charley (Strathclyde University, Glasgow) vinda em nome do grupo que organizava (1986-1995) as conferências internacionais itinerantes da BISS - Bartlett International Summer School, nas quais Phil foi interlocutor assíduo. O texto foi mantido no original, em inglês, por soar mais fiel.

A redação da introdução da exposição ficou a cargo da Telma, que também escolheu e legendou as fotos por ela selecionadas e disponibilizadas. A exposição foi organizada no NAP/PLAC-USP e produzida no Laboratório de Produção Gráfica da FAUUSP. 
"I first met Phil on a train leaving Victoria Station on the way to a Bartlett International Summer School in Brussels. He was in many ways typical of BISS members. Combative, a worker in the field of the built environment and able to argue about Marx until the bottle was empty on the table. 'You know Jonathan, I often like to start a meeting off by telling the others, I am a Marxist and if you don't like it, then...' On subsequent family visits to Brasil I met him and his family in Sao Paulo on a number of occasions and it was always gratifying to find that whereas many had given up the fight he was as committed as ever to building his own radical agenda as to how we might understand and intervene in the way we make buildings and cities. Indeed on my last trip two years ago in typical Phil style I

accompanied him on two day trips, one to the Toyota factories where he provided me with a commentary on the fate of the car industry and industrial buildings in the Sao Paulo area, and another to meet local politicians involved in a community participation scheme in Sao Andre. The news of his untimely death came as a shock to myself and other comrades in Europe and he will be sorely missed, there are too few individuals like him working these days in the academic world."

Jonathan Charley

Member,

Bartlett Internatinal Summer School

Essa exposição reúne uma pequena mostra das cerca de 5.000 mil fotos feitas pelo professor titular e pesquisador da FAUUSP, Philip Gunn, no período de 1995 a 2005, no âmbito do projeto de pesquisa intitulado "Vilas e Núcleos Fabris: Brasil, 1811-2005", desenvolvido com Telma de Barros Correia, professora associada e pesquisadora do Departamento de Arquitetura e Urbanismo, da EESC-USP. A pesquisa contou com apoio da Fapesp, que financiou os levantamentos na região Sul, e do CNPq, por meio da Bolsa de Produtividade em Pesquisa.

A intenção da pesquisa foi investigar a forma (em termos da arquitetura e do desenho urbano) e o significado (em termos de organização do território e da moradia) que a emergência das vilas operárias em áreas urbanas e suburbanas e de núcleos residenciais, no campo, teve no Brasil, no período entre a emergência da indústria moderna na primeira metade do século 19 e o início do século 21. Seu programa foi baseado em duas atividades principais: pesquisa bibliográfica e em fontes primárias e programa de visitas a locais onde existem - ou existiram - vilas e núcleos fabris. A pesquisa identificou e reuniu informações sobre cerca de 400 vilas operárias e núcleos fabris, dos quais próximo de 200 foram visitados.

No Brasil, a partir, sobretudo, da segunda metade do século 19, difundiu-se largamente a prática de construção de moradias por empresas para seus operários em cidades ou no campo. No território nacional, esses assentamentos estão ligados a indústrias (têxteis, de papel, de cimento, de vidro, siderúrgicas, etc.), a empresas de mineração, a usinas de açúcar, a madeireiras, a empresas de geração de energia, a companhias ferroviárias e a frigoríficos.

Esse período, de quase 200 anos, permite acompanhar um longo ciclo da história desses lugares, no qual emergem em diferentes formas (vilas operárias e núcleos fabris, com tamanhos, desenhos e programas diversos), com vários estilos arquitetônicos (neoclássico, eclético, missões, e moderno de diversas vertentes) e com diferentes tipos de moradias (casas isoladas, geminadas ou em blocos, prédios de apartamentos e alojamentos coletivos).

Ao longo desse período também é possível registrar e acompanhar vários momentos na trajetória das vilas e núcleos: sua fundação, expansão, usual descaracterização, eventual transformação em cidade e, em muitos casos, destruição. Com esse olhar buscou-se contar parte da história de um amplo movimento de construção, transformação e destruição de moradias, correlato às transformações ininterruptas, com seus constantes ajustes e incertezas perenes, que distinguem o mundo industrial.

Ao longo de cerca de dez anos essa pesquisa foi uma atividade muito gratificante, desenvolvida com grande entusiasmo, em que se mesclaram o prazer com as descobertas e as novas indagações que surgiam, com o fascínio de conhecer melhor os meandros do Brasil e de seu povo, visitando lugares, colhendo informações em arquivos, fábricas, prefeituras e bibliotecas, conversando com pessoas. Para Phil, significou, ainda, praticar a sua grande paixão: a fotografia, todas aqui de sua autoria. 


\section{AS EXPERIÊNCIAS PIONEIRAS, I8II-I880}

No período entre 1811 e 1880, quatro setores tiveram uma ação expressiva no Brasil em relação à criação de casas para seus empregados: os engenhos de açúcar; as fábricas de ferro, as minas e as indústrias têxteis.

\section{Os Engenhos de Açúcar}

No Brasil, desde o período colonial, pequenos povoados se formaram junto dos engenhos de açúcar, reunindo, geralmente, uma capela, o engenho e seus anexos, uma casa grande, moradias para trabalhadores livres e para escravos.

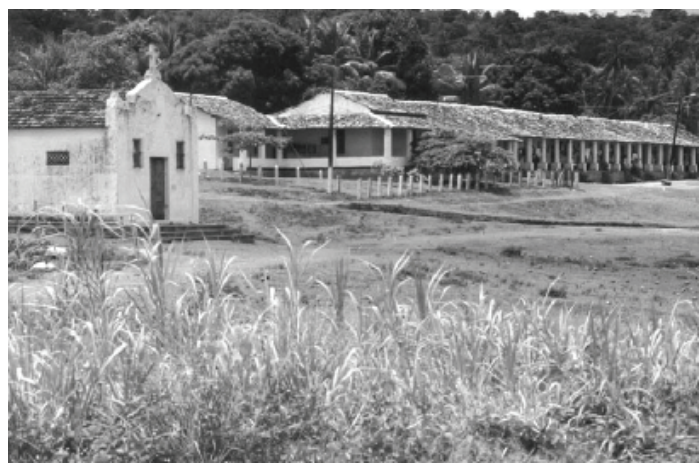

Ipojuca, Pernambuco

Capela e senzalas do Engenho Tinoco, 1995

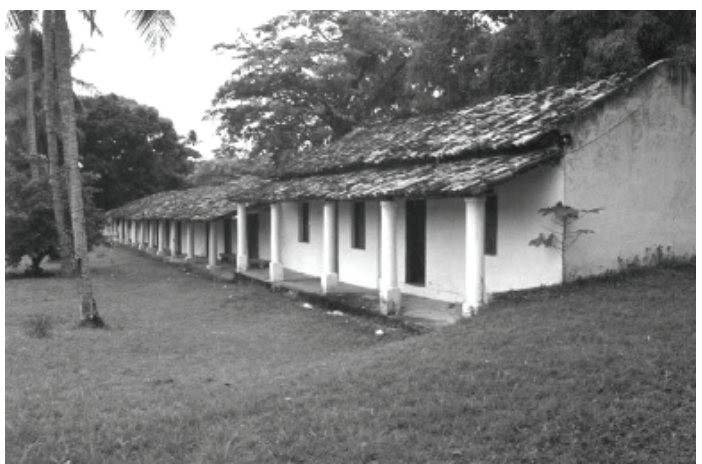

Igarassu, Pernambuco

Senzalas do Engenho Monjope, 1998

\section{As Fábricas de Ferro}

No século 19 muitas moradias para trabalhadores foram erguidas no Brasil, especialmente no estado de Minas Gerais, por forjas e fábricas de ferro. Nesse estado, dezenas de pequenas forjas surgiram, geralmente incluindo a construção de uma casa para a administração e outra para o mestre ferreiro e de ranchos para os operários ou escravos.

Alguns núcleos fabris mais amplos foram gerados por fábricas de ferro de maior porte, como a Real Fábrica de Ferro de São João de Ipanema (1811), a Fábrica de Ferro do Prata (1812), a fábrica do Morro do Pilar (1812) e a Fábrica de São Miguel de Piracicaba (1827). O primeiro desses núcleos se situava no estado de São Paulo e os demais no de Minas Gerais.

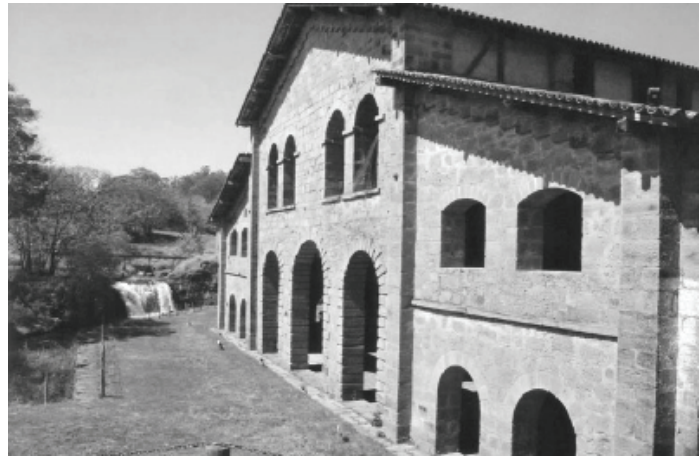

Iperó, São Paulo -

Prédios fabris da Real Fábrica de Ferro de São João de Ipanema, 2004

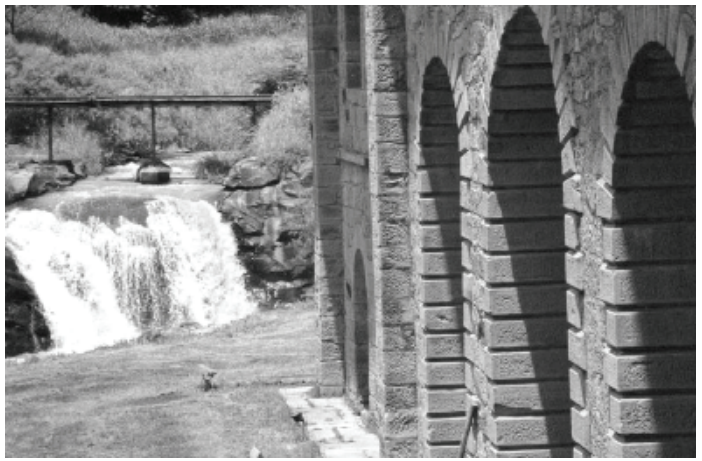

Iperó, São Paulo

Prédios fabris da Real Fábrica de Ferro de São João de Ipanema, 2001 


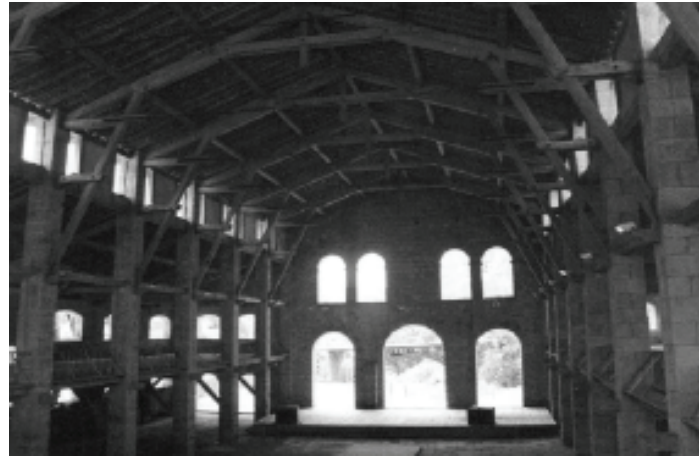

Iperó, São Paulo

Prédios fabris da Real Fábrica de Ferro de São João de Ipanema, 2001

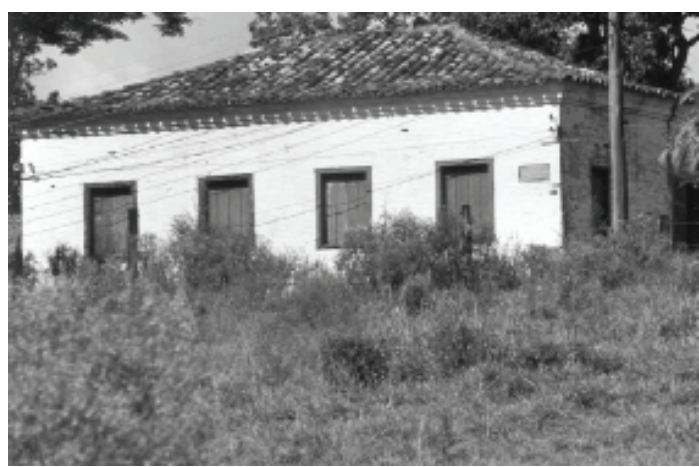

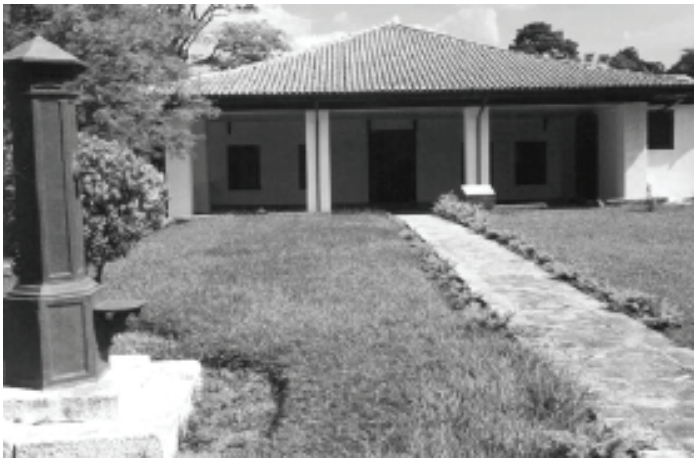

Iperó, São Paulo

Casa do diretor da Real Fábrica de Ferro de São João de Ipanema, 2001
Iperó, São Paulo

Casa de funcionário da Real

Fábrica de Ferro de São João de

Ipanema, 2001

\section{As Empresas de Mineração}

Em Minas Gerais, a atividade mineradora gerou pequenos núcleos residenciais em propriedades privadas desde o período colonial. No século 19, um núcleo de grande porte surgiu, criado pela Mina de Morro Velho, que a partir de 1834 pertenceu à empresa The Saint John D'El Rey Mining Company.

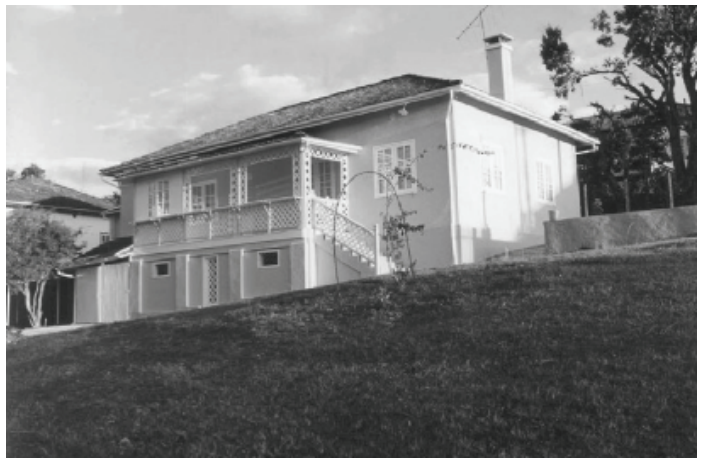

Nova Lima, Minas Gerais

Casas para gerentes da Mina de Morro Velho, 1998

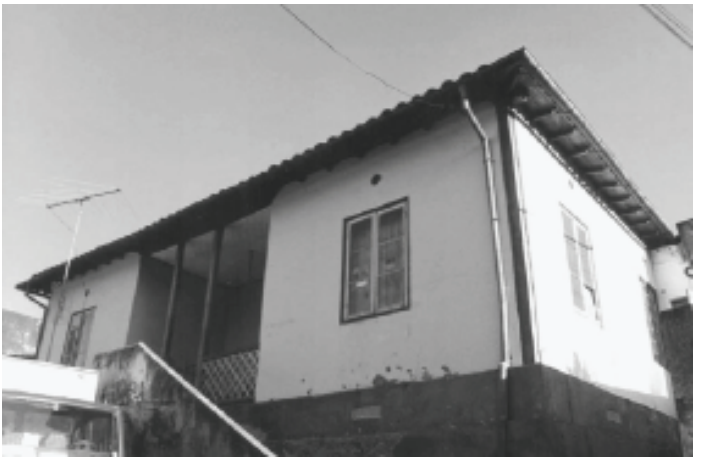

Nova Lima, Minas Gerais

Casas para gerentes da Mina de Morro Velho, 1998 


\section{As Fábricas Têxteis}

Entre meados do século 19 e 1880, diversas fábricas têxteis localizadas no campo devido, especialmente, à busca de proximidade com matas e cachoeiras, exploradas como fonte de energia criaram habitações para seus empregados.

Nesse período, essas indústrias deram ênfase à contratação de operários - sobretudo mulheres - solteiros, os quais eram abrigados em alojamentos coletivos. Além desses alojamentos, entretanto, os núcleos fabris dessas indústrias costumavam reunir algumas casas, capela e escola.

Entre as indústrias têxteis que criaram núcleos fabris no Brasil, até 1880, estão as fábricas: Todos os Santos; Esther (1849); Fernão Velho (1857); Brasil Industrial (1871); Cedro (1872); Petropolitana (1874); Carioba (1875); Biribiri (1876); Gabiroba (1876); Santa Francisca (1876) e Cachoeira (1877).

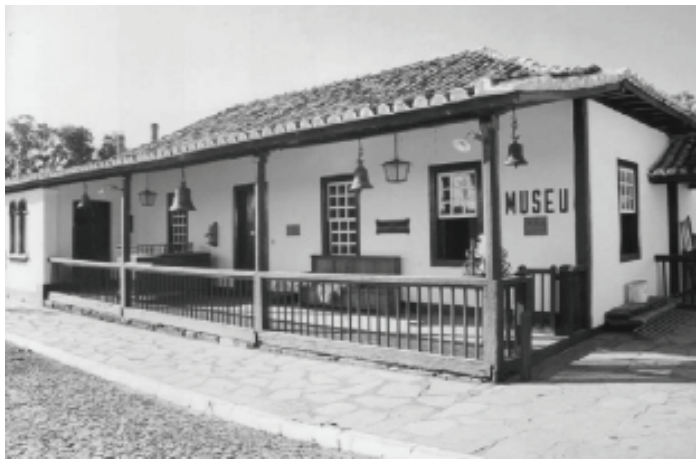

Caetanópolis, Minas Gerais

Casa do diretor da Fábrica de Tecidos Cedro, 1998

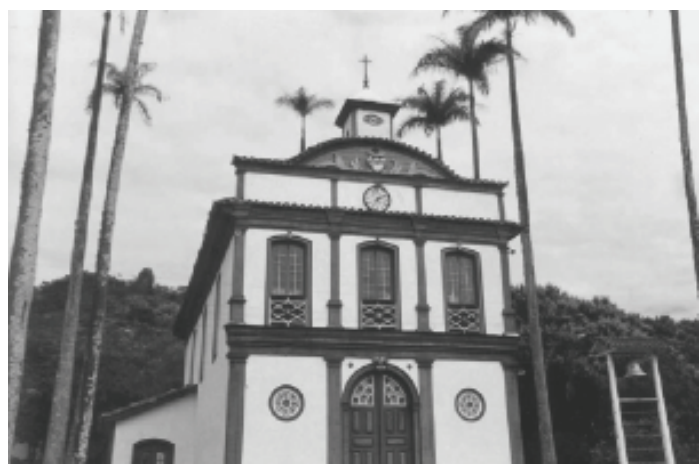

Diamantina, Minas Gerais

Biribiri, núcleo fabril criado pela Fábrica de Fiação e Tecidos Biribiri, 1998

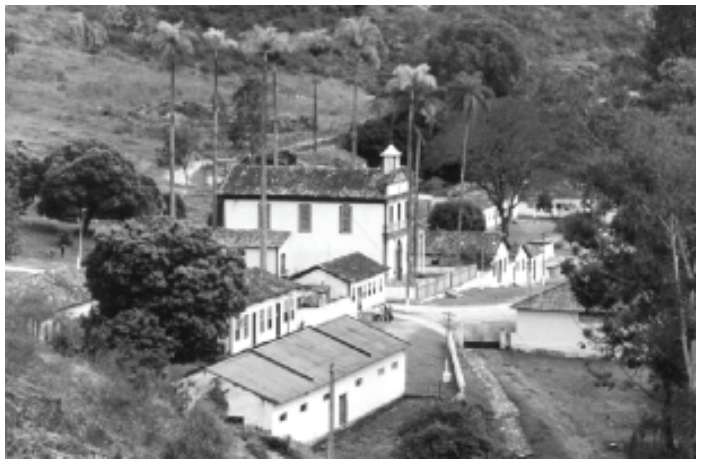

Diamantina, Minas Gerais

Biribiri, núcleo fabril criado pela Fábrica de Fiação e Tecidos Biribiri, 1998

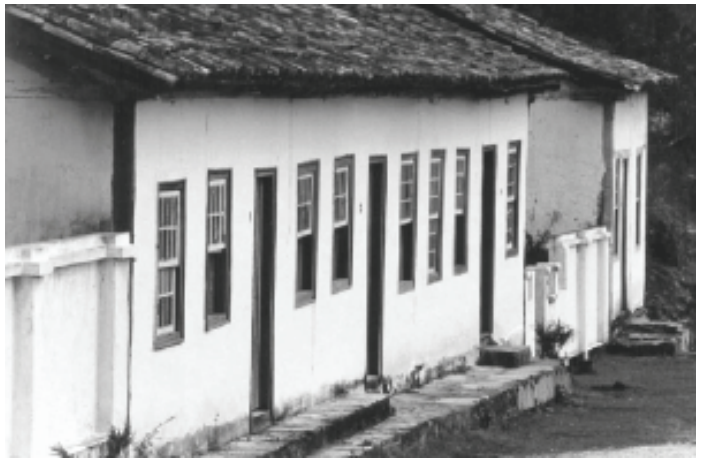

Diamantina, Minas Gerais

Biribiri, núcleo fabril criado pela Fábrica de Fiação e Tecidos Biribiri, 1998

\section{A DIFUSÃO NACIONAL DOS ASSENTAMENTOS FABRIS, I88I-I930}

No Brasil, entre 1880 e 1930, os conjuntos de moradias erguidos por empresas para seus funcionários difundem-se em larga escala, em diferentes estados e regiões.

Nesse momento, esses espaços se afirmam como uma importante expressão da era industrial não apenas por suas origens, usos, funções e conflitos sociais, como também por suas características formais, que usualmente remetem a valores, materiais e símbolos do mundo fabril. 
Na arquitetura desses lugares, nesse período, surge freqüentemente exemplares inspirados em modelos tradicionais brasileiros. O padrão urbano de casas de porta e janela dispostas em renque e desprovidas de recuos frontais ou laterais foi, nesse momento, bastante comum em vilas operárias e núcleos fabris.

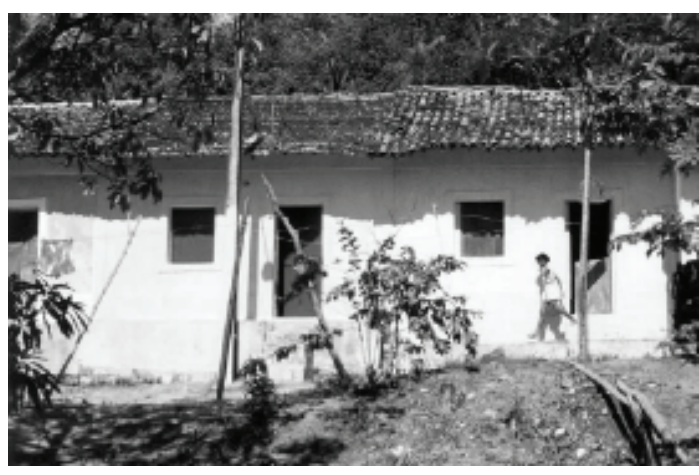

Paulista, Pernambuco

Núcleo fabril criado pela Companhia de Tecidos Paulista, 1995

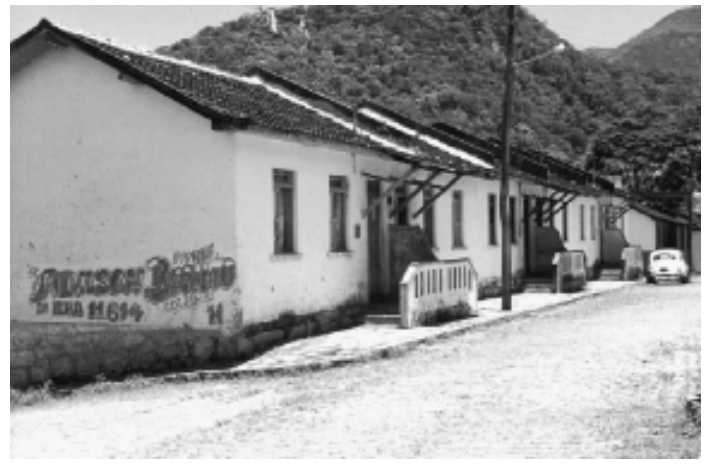

Magé, Rio de Janeiro

Casas em Pau Grande, núcleo fabril erguido pela Fábrica de Fiação e Tecidos Pau Grande, 1998

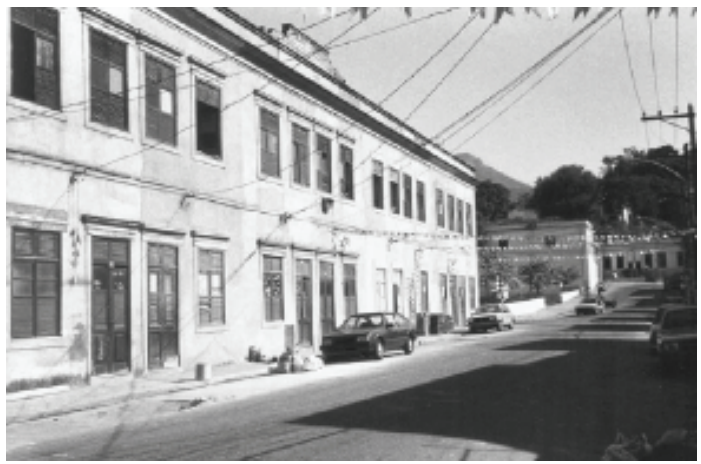

Rio de Janeiro

Casas erguidas pela Companhia de Fiação e Tecidos Confiança Industrial, 1998

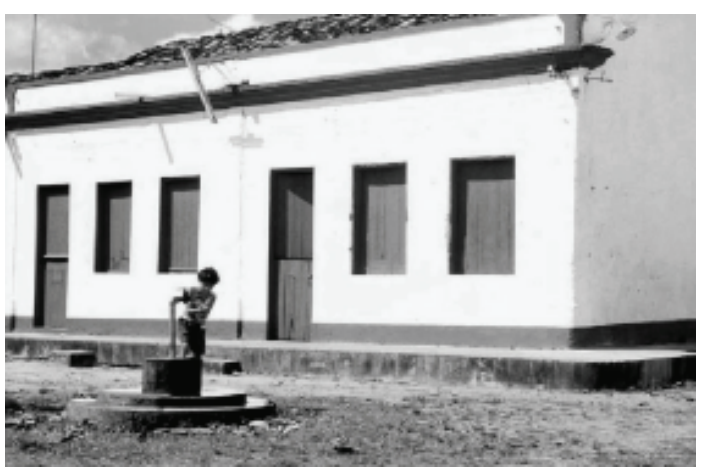

Neópolis, Sergipe

Núcleo fabril criado pela Fábrica da Passagem, 1995

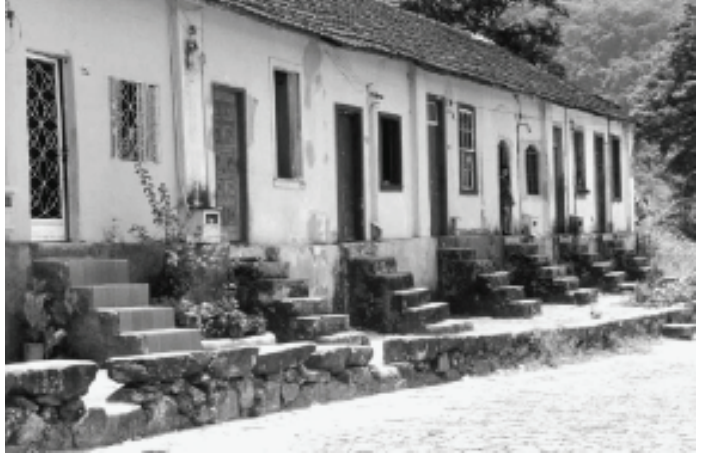

Petrópolis, Meio da Serra, Rio de Janeiro

Casas erguidas pela Companhia de Fiação Cometa, 1998

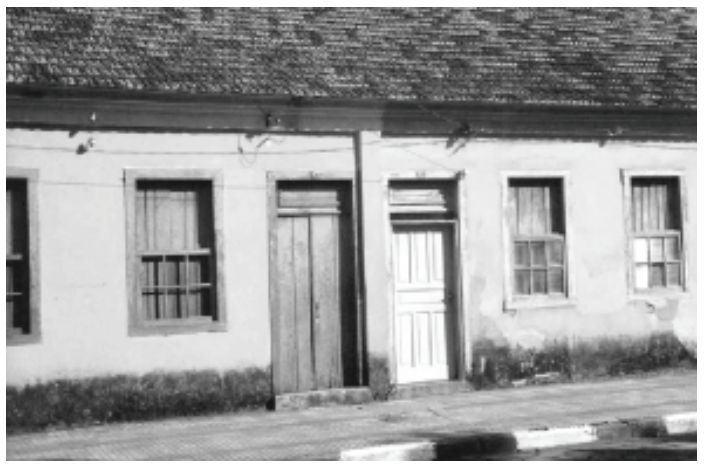

Tatuí, São Paulo

Vila operária da Companhia de Fiação e Tecelagem São Martinho, 2001 


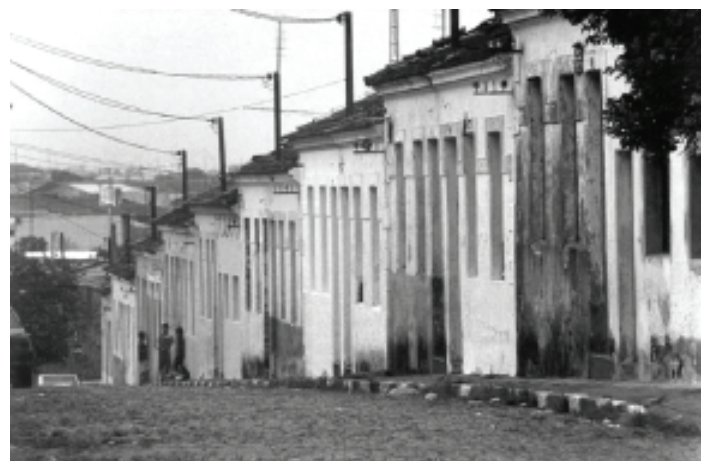

Itu, São Paulo

Vila operária da Companhia de Fiação e Tecelagem São Pedro, 2001

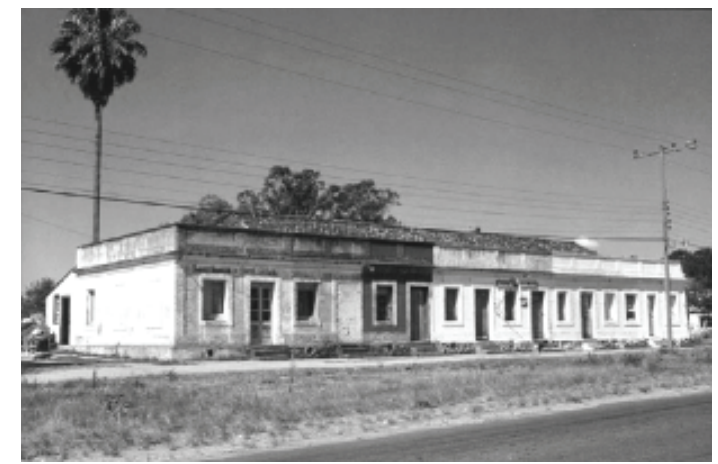

Bagé, Rio Grande do Sul

Casas erguidas pela Charqueada Santa Thereza, 1997

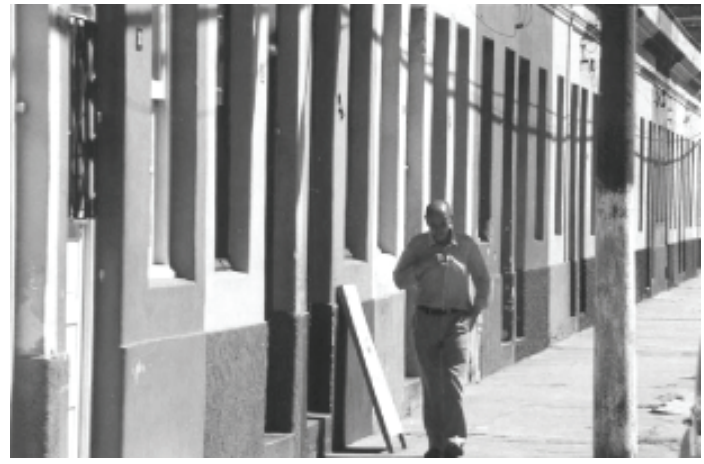

Rio Grande, Rio Grande do Sul Casas erguidas pela Indústria de Tecidos Rheingantz, 1997

Em alguns casos, grupos de casas semelhantes recebem alpendres frontais, que remetem à arquitetura de senzalas erguidas em engenhos de açúcar do Nordeste durante o período colonial e o século 19.

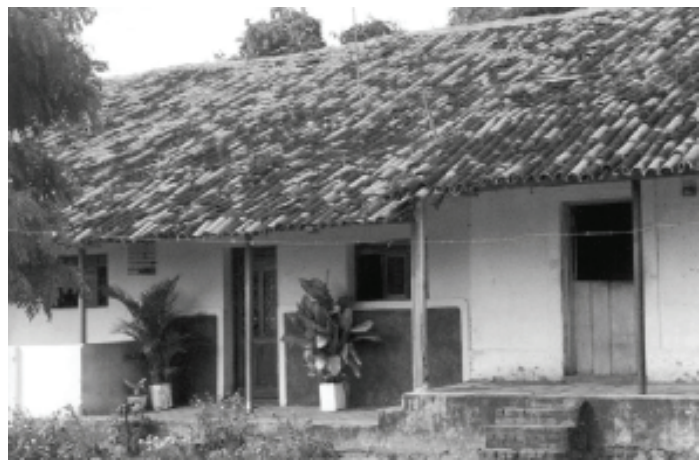

Rio Tinto, Paraíba

Núcleo fabril criado pela Companhia de Tecidos Rio Tinto, 1995

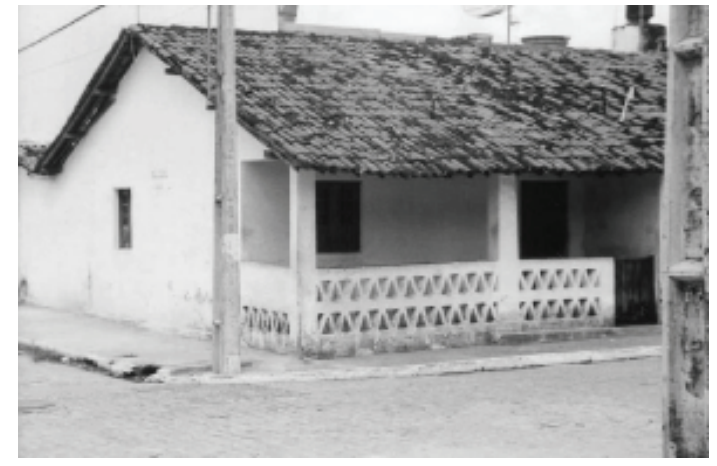

Recife, Pernambuco

Casa na vila operária erguida pelo Cotonifício Othon Bezerra de Mello S.A., 2003 


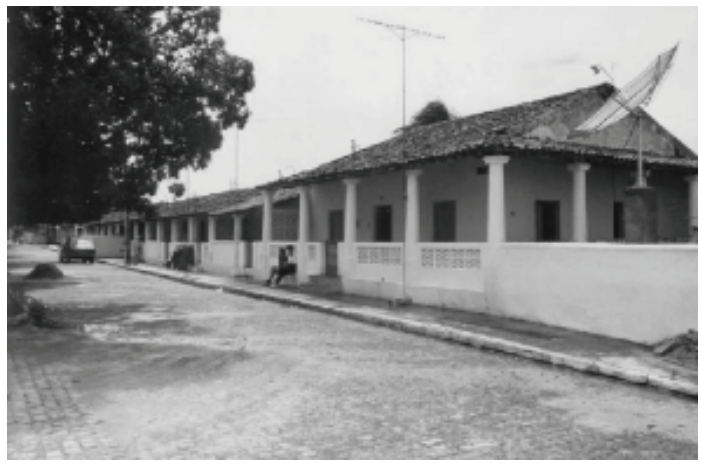

Delmiro Gouveia, Alagoas

Núcleo fabril criado pela

Fábrica da Pedra, 1995

Inovações higienistas do final do século 19 se fazem presente na arquitetura de vilas operárias e núcleos fabris: o porão alto é raro, enquanto o recuo lateral freqüente.

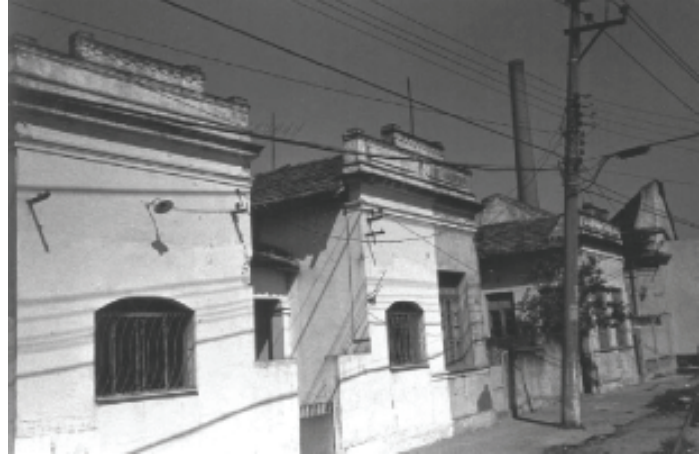

Rio de Janeiro

Casas erguidas pela Fábrica de Tecidos América Fabril, 1998

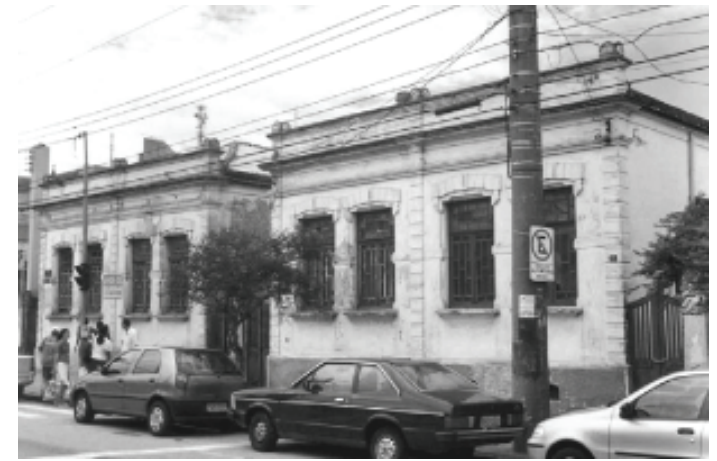

Jundiaí, São Paulo

Casas da Fábrica São Bento, 2002

Nas primeiras décadas do século 20 os chalés que povoaram a paisagem dos subúrbios brasileiros também se difundiram amplamente em vilas operárias e núcleos fabris. Podiam remeter a modelos europeus, incluir ornatos ou assumir formas despojadas.

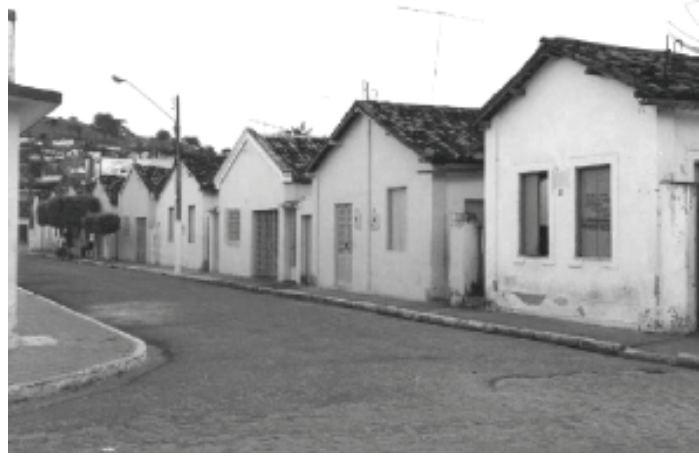

Timbaúba, Pernambuco

Casas erguidas pela Fiação e Tecelagem Timbaúba, 2005

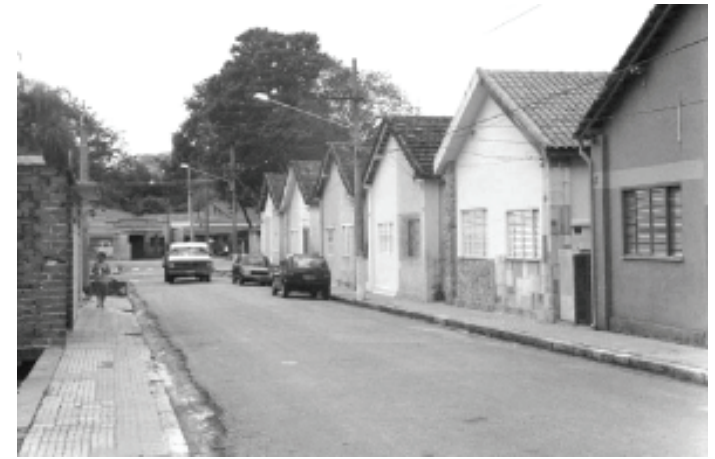

Votorantim, São Paulo

Casas erguidas pela Fábrica de Estamparia e Alvejaria Votorantim, 2001 


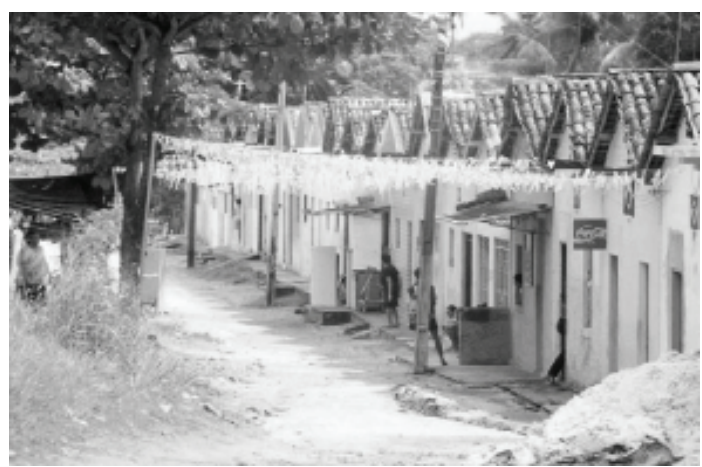

Santa Rita, Paraíba

Vila operária da Companhia de Tecidos Paraibana, 2002

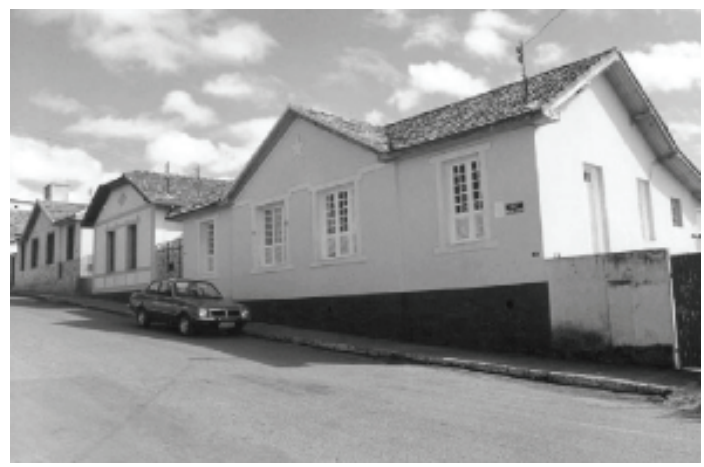

Itabirito, Minas Gerais

Chalés pertencentes à Companhia Industrial Itabira do Campo, 1998

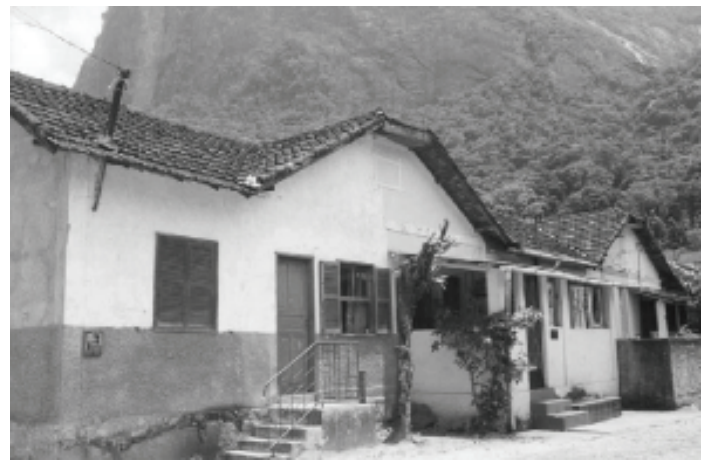

Petrópolis, Meio da Serra, Rio de Janeiro

Casas erguidas pela Companhia de Fiação Cometa, 1998

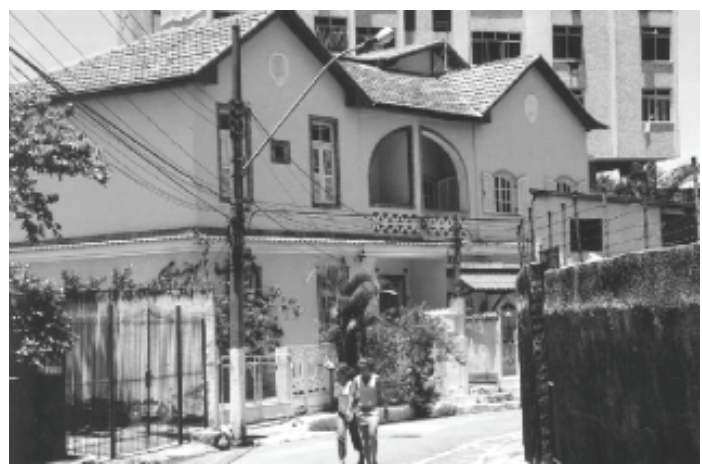

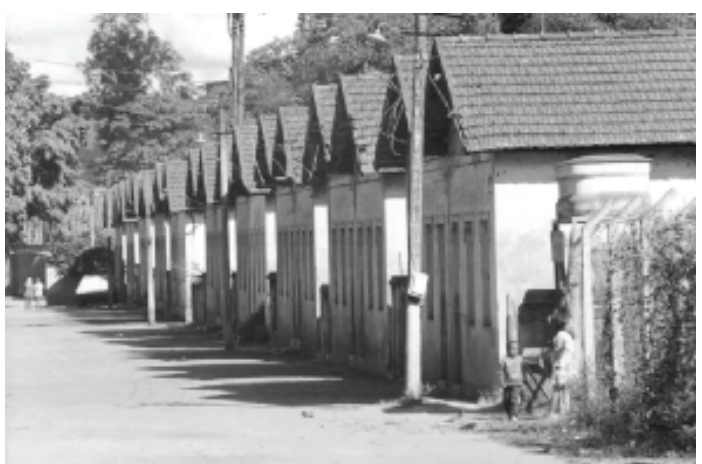

Itabirito, Minas Gerais

Chalés pertencentes à Valadares Diesel Ltda., 1998

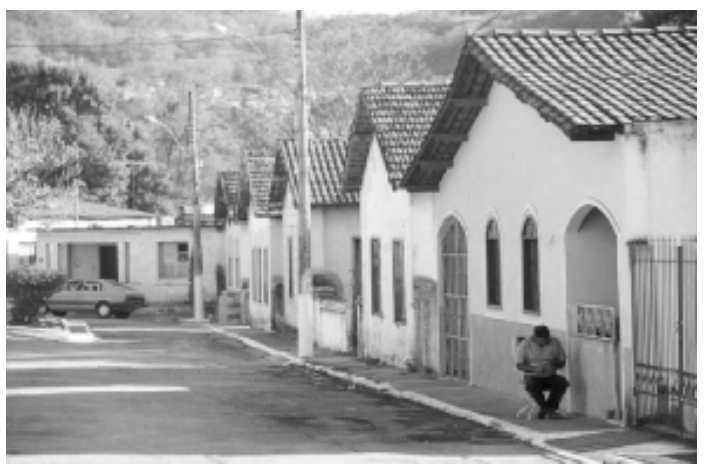

Cachoeira do Prata, Minas Gerais

Chalés no núcleo fabril da Companhia Têxtil Cachoeira de Macacos, 1998

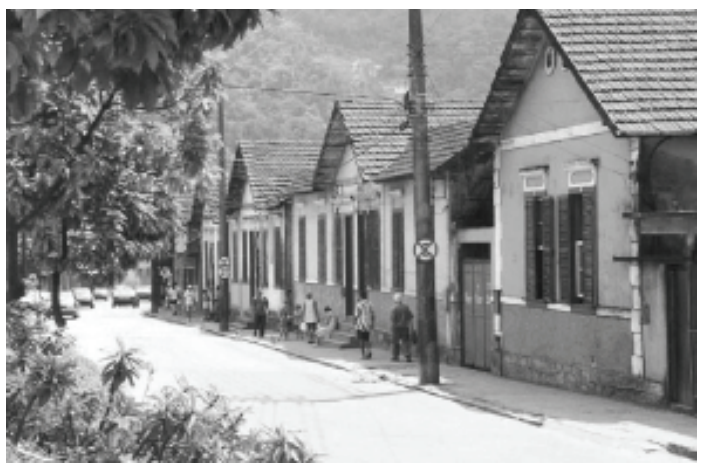

Petrópolis, Rio de Janeiro

Casas erguidas pela Companhia de Fiação Cometa, 1998

Niterói, Rio de Janeiro

Vila operária da Companhia

Commercio e Navegação, 2004 


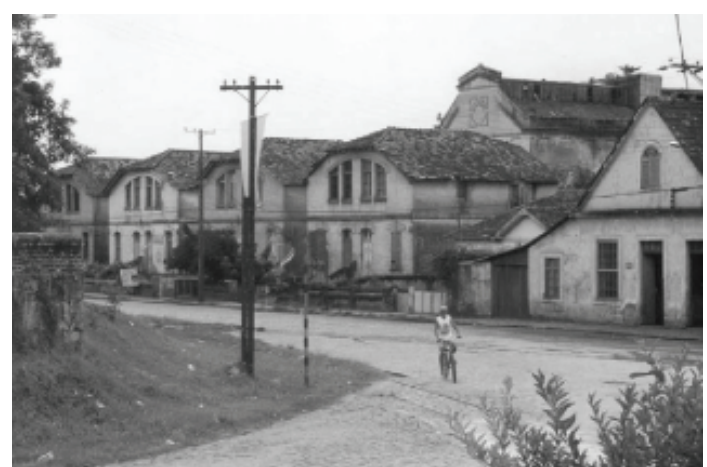

Antonina, Paraná

Casas erguidas pelo Moinho Matarazzo, 1997

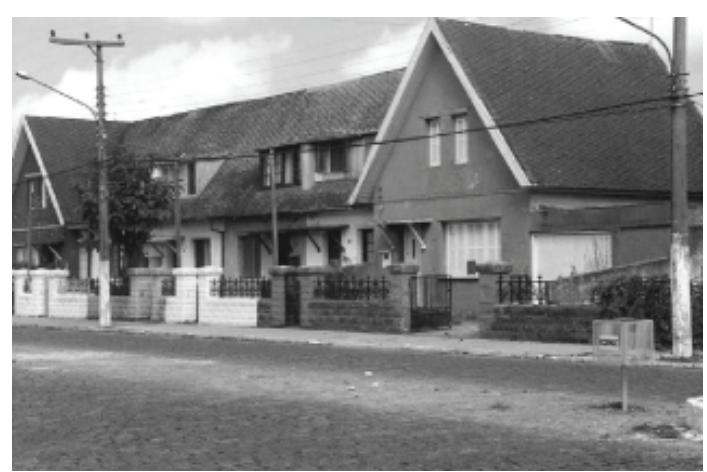

Rio Grande, Rio Grande do Sul

Casas erguidas pela Indústria de Tecidos Rheingantz, 1997

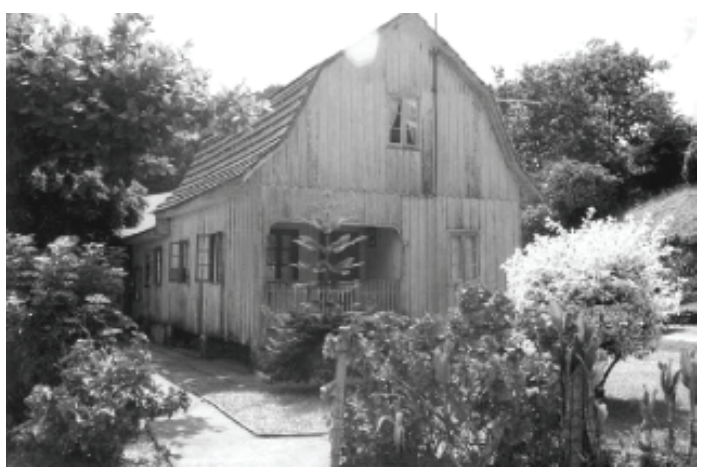

Blumenau, Santa Catarina

Casa erguida pela Garcia, 1997

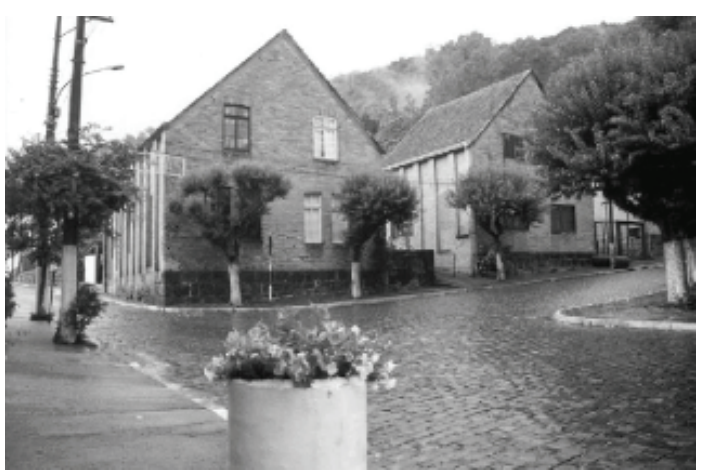

Galópolis, Rio Grande do Sul

Núcleo fabril criado pelo Lanifício São Pedro de Galópolis, 1997

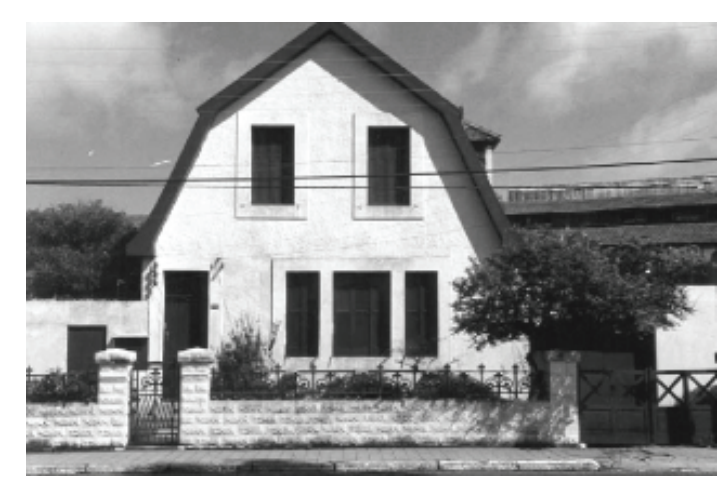

Rio Grande, Rio Grande do Sul

Casas erguidas pela Indústria de Tecidos Rheingantz, 1997

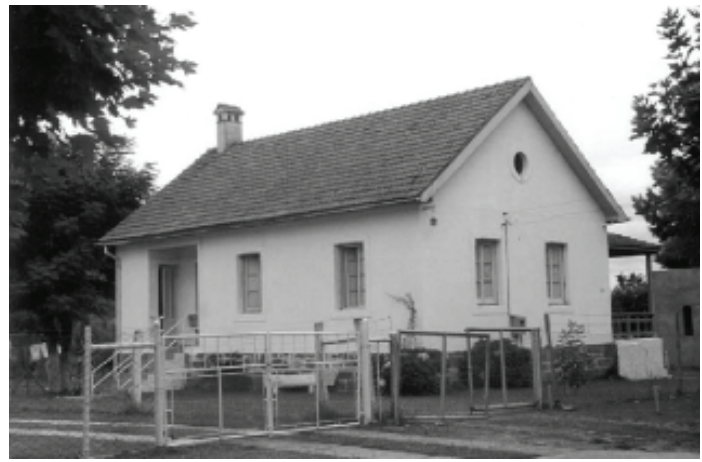

Rio Grande, Rio Grande do Sul

Casa erguida pelo Frigorífico Armour, 1997

Em algumas vilas operárias e núcleos fabris criados nesse período emerge uma estética tipicamente industrial, expressa na simplificação ou ausência de ornatos. O tijolo aparente usado em fábricas, moradias, igrejas, etc., torna-se um elemento característico do despojamento que baliza essa nova paisagem industrial. 


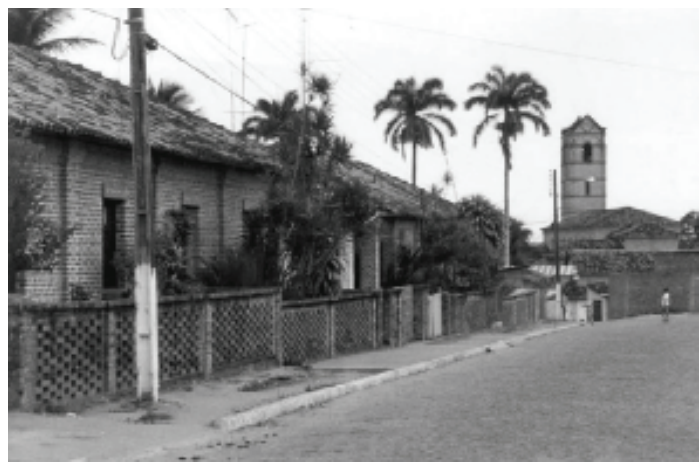

Rio Tinto, Paraíba

Casas e igreja edificadas pela Companhia de Tecidos Rio Tinto, 1995 e 2001

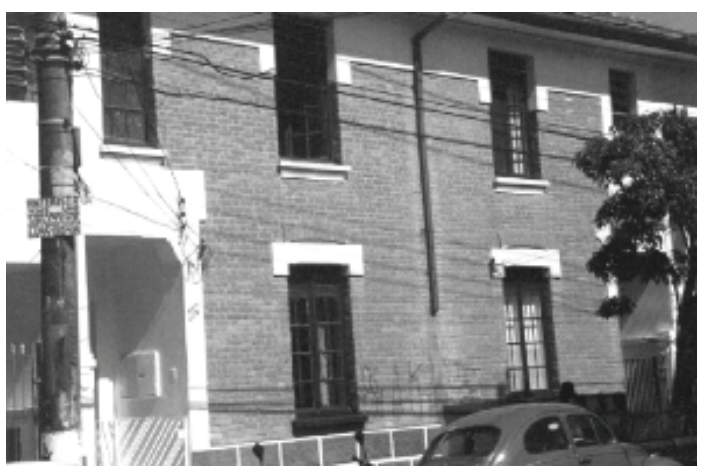

São Paulo

Vila Cerealina, erguida pelas Indústrias Reunidas Matarazzo, 2001

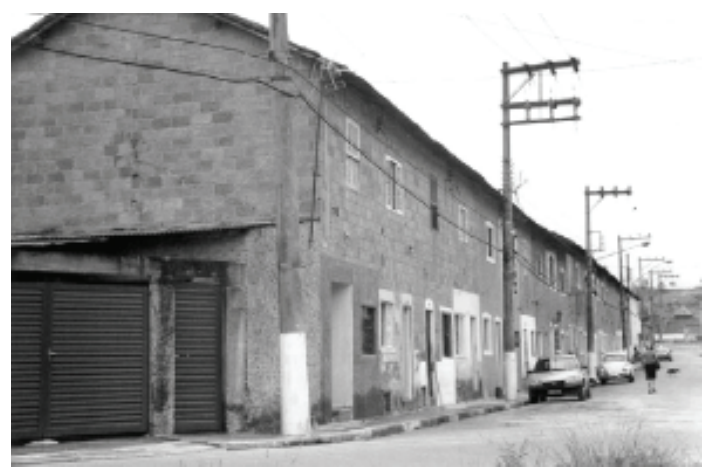

Votorantim, São Paulo

Casas erguidas pela Fábrica de Estamparia e Alvejaria Votorantim, 2001

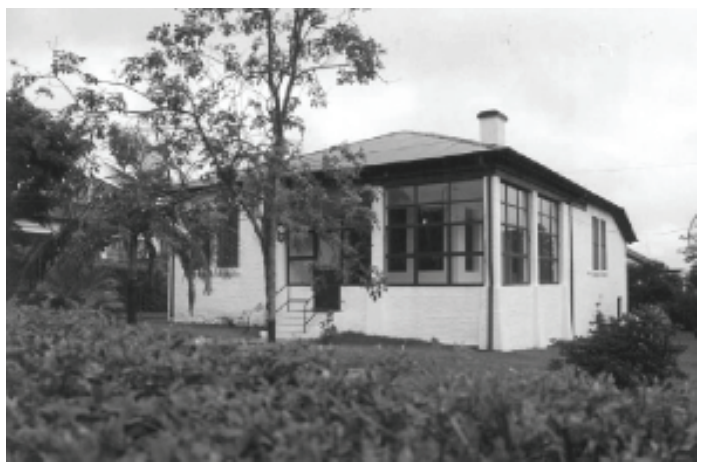

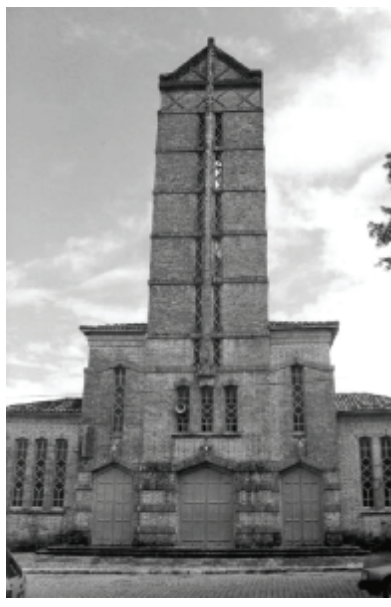

1 Rio Tinto, Paraíba

H. Casas e igreja

edificadas pela

Companhia de Tecidos

Rio Tinto, 1995 e 2001
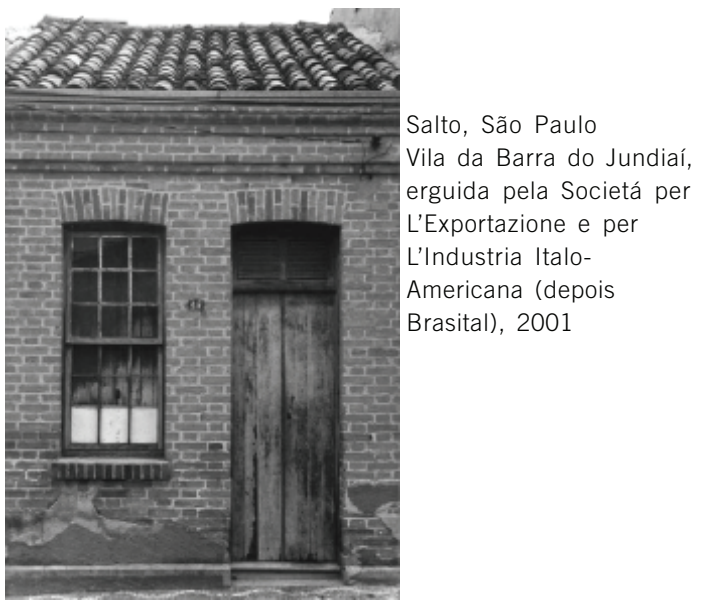

sital), 2001

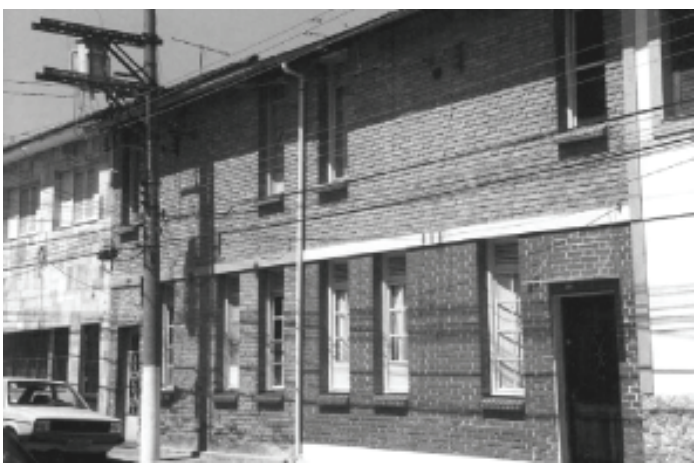

São Paulo

Vila Boyes, construída pela Fábrica São Simeão, 2001

Rosário, Rio Grande do Sul

Casa erguida pela Swift,

1996 
Em alguns casos raros, a estética industrial se expressa na arquitetura de vilas operárias por meio de ornatos cujos temas remetem ao mundo das máquinas.

Um exemplo, nesse sentido, é a Vila Maria Zélia, edificada entre 1916 e 1920, onde desenhos no reboco de fachadas compõem quadriláteros sugerindo chapas de metal, pequenos prismas que remetem a parafusos e formas circulares os quais lembram manivelas.

É também o caso da igreja da vila operária do Cotonifício Othon Bezerra de Mello S.A., em Recife, na qual os desenhos dos óculos se inspiram na forma de engrenagens industriais.

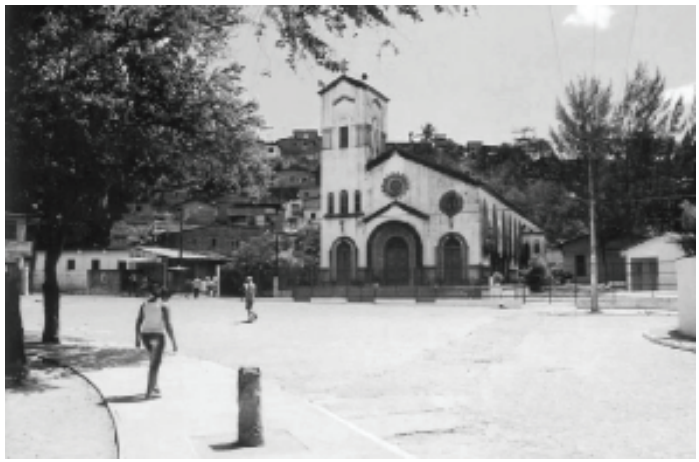

Recife, Pernambuco

Igreja de sua vila operária do Cotonifício Othon Bezerra de Mello S.A., 2003

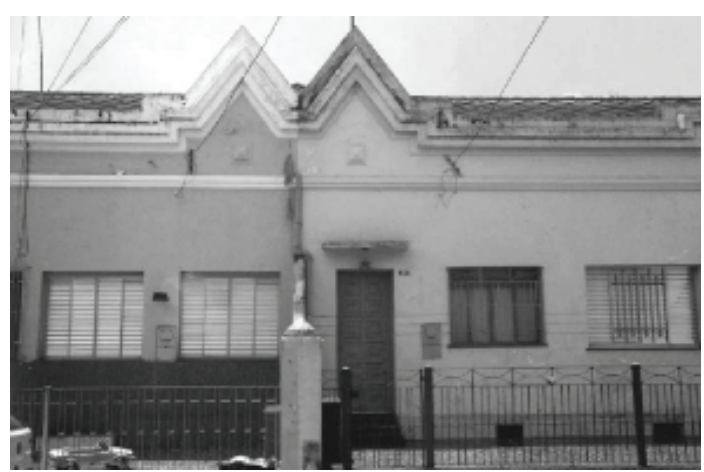

São Paulo

Vila Maria Zélia, criada pela Companhia Nacional de Tecidos de Juta, 2001

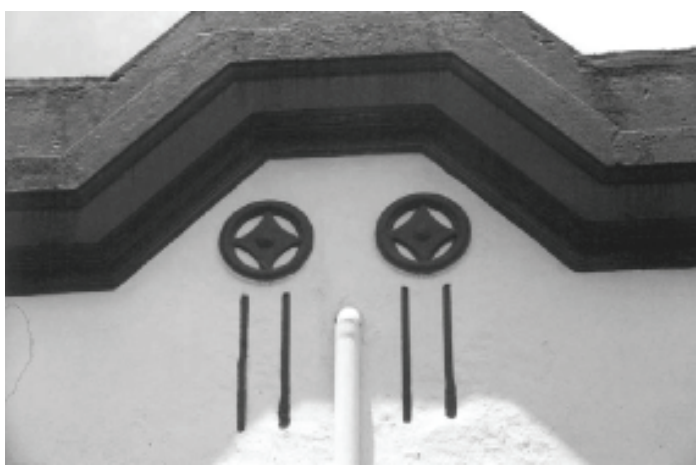

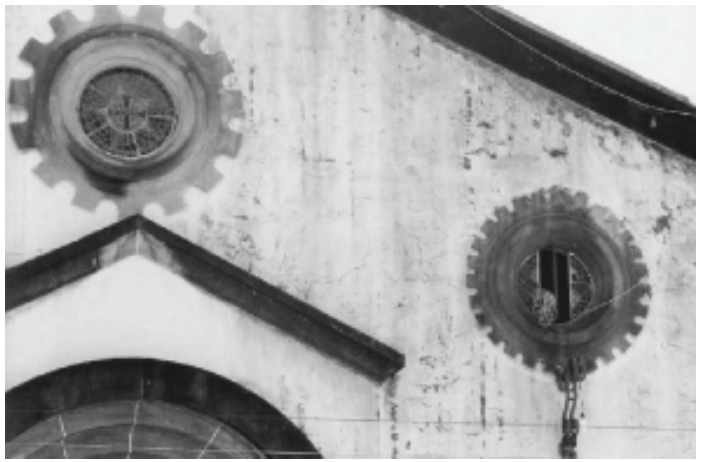

Recife, Pernambuco

Igreja de sua vila operária do Cotonifício Othon Bezerra de Mello S.A., 2003

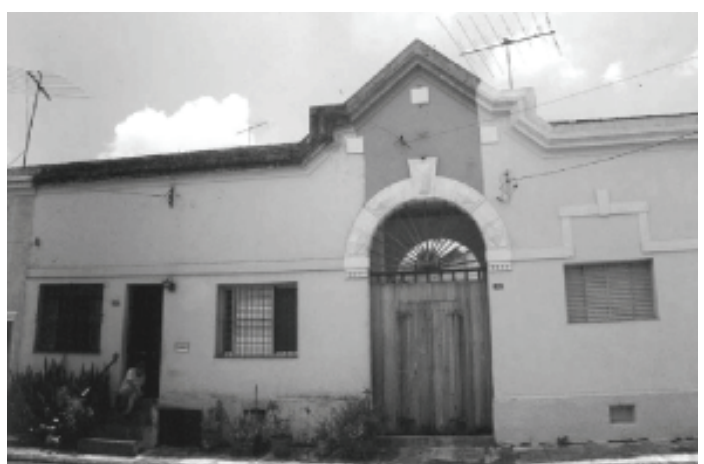

São Paulo

Vila Maria Zélia, criada pela Companhia Nacional de Tecidos de Juta, 2001

São Paulo

Vila Maria Zélia, criada pela Companhia

Nacional de Tecidos de Juta, 2001 


\section{A AFIRMAÇÃO DO MODELO, I93I-I960}

Nas décadas de 30, 40 e 50 os conjuntos residenciais de empresas continuaram a difundir-se no Brasil em grande escala: novos conjuntos são criados e muitos dos existentes se ampliam.

$\mathrm{Na}$ arquitetura desses lugares, nas décadas de 30 e 40 foi significativa a difusão de uma vertente modernista que, posteriormente, seria identificada como art-déco, da tipologia que se popularizou no Brasil com o nome de "bangalô" e do estilo "missões".

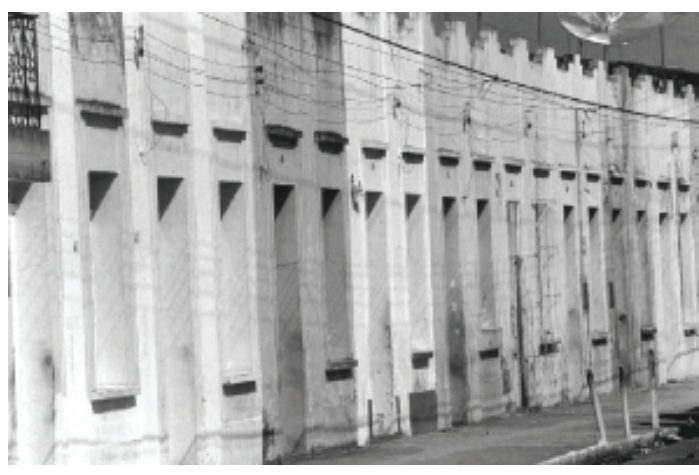

Goiana, Pernambuco

Casas para operários, 2000

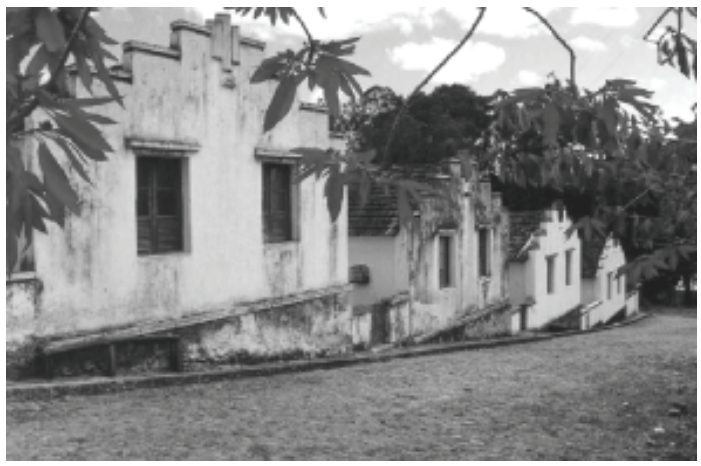

Diamantina, Minas Gerais

Gouveia, núcleo fabril criado pela Companhia Industrial São Roberto, 1998

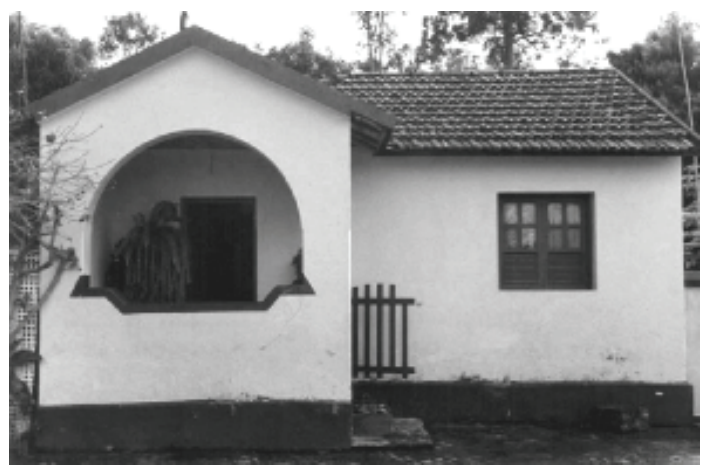

Diamantina, Minas Gerais

Gouveia, núcleo fabril criado pela Companhia Industrial São Roberto, 1998

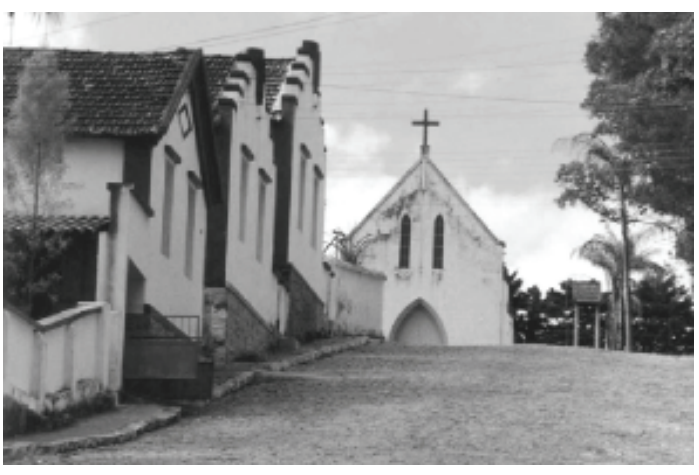

Diamantina, Minas Gerais

Gouveia, núcleo fabril criado pela Companhia Industrial São Roberto, 1998

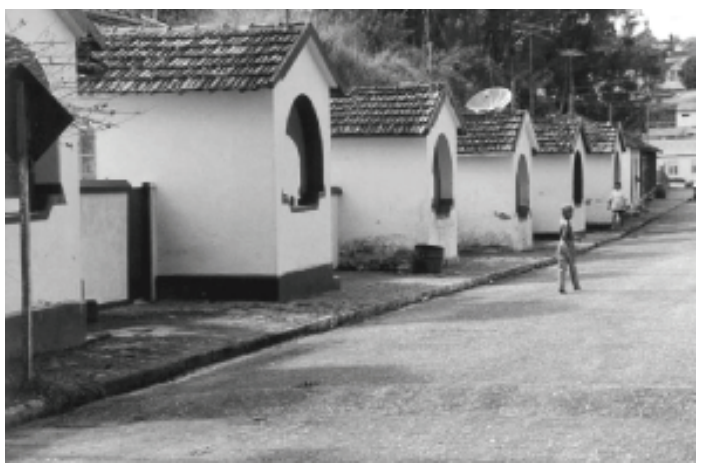

Diamantina, Minas Gerais

Gouveia, núcleo fabril criado pela Companhia Industrial São Roberto, 1998

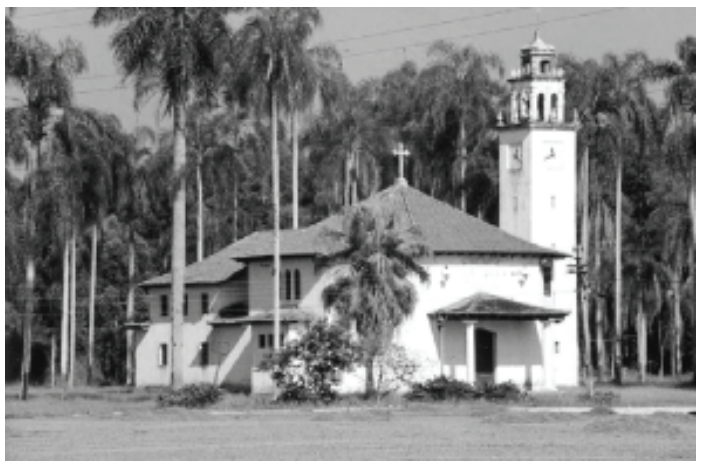

Pindamonhangaba, São Paulo

Igreja e casas construídas pela Companhia Agrícola e Industrial Cícero Prado, 2001 


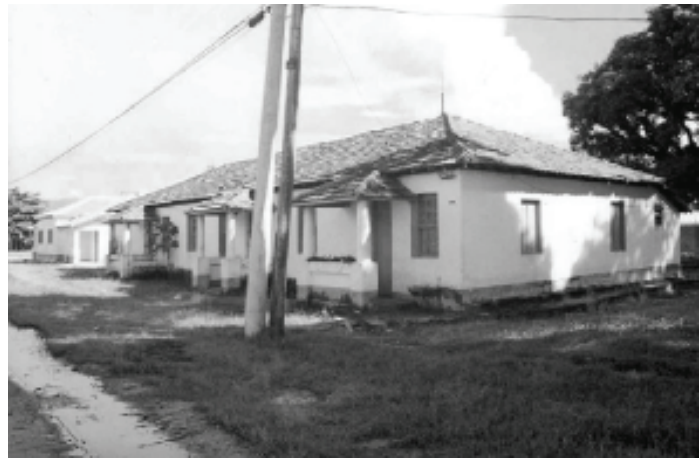

Pindamonhangaba, São Paulo

Igreja e casas construídas pela Companhia Agrícola e Industrial Cícero Prado, 2001

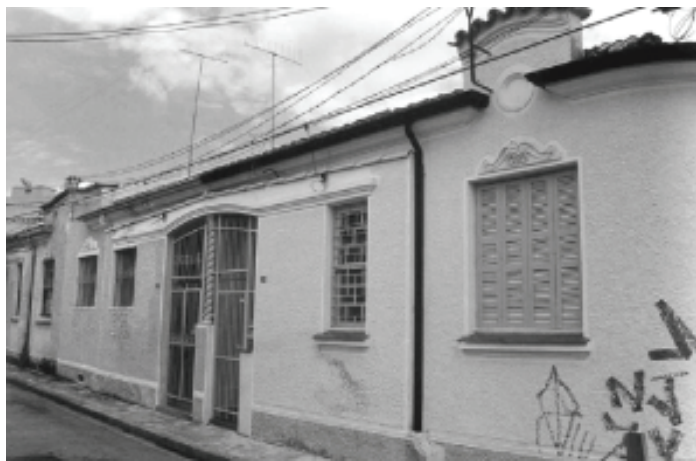

Jundiaí, São Paulo

Vila Argos, construída pela Argos Industrial S. A., 2002

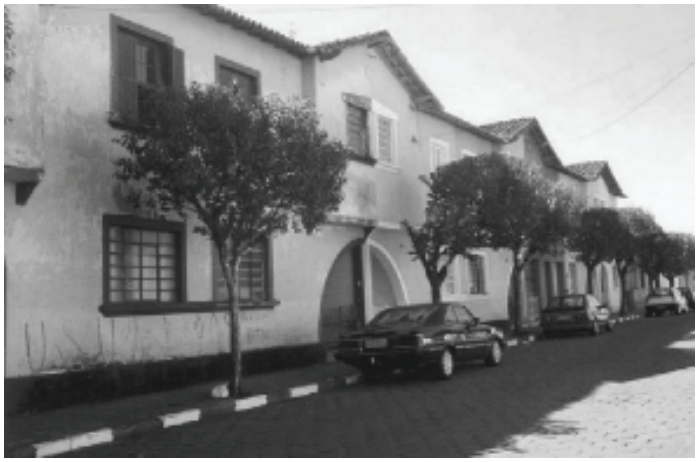

Araraquara, São Paulo

Vila operária da Indústria de Meias Lupo, 2003

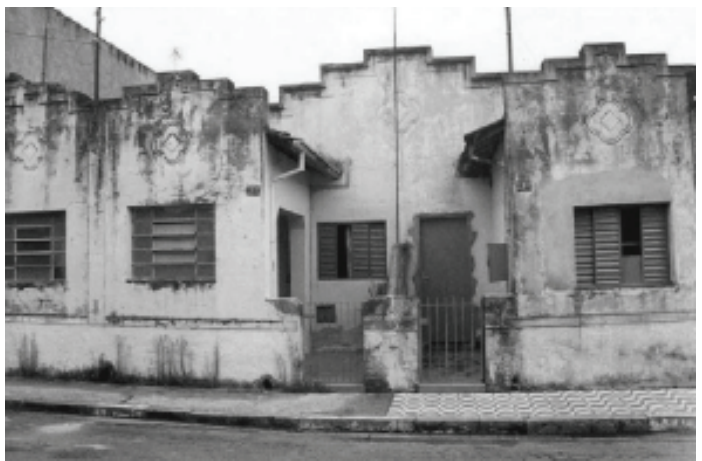

Votorantim, São Paulo

Casas erguidas pela Fábrica de Estamparia e Alvejaria Votorantim, 2001

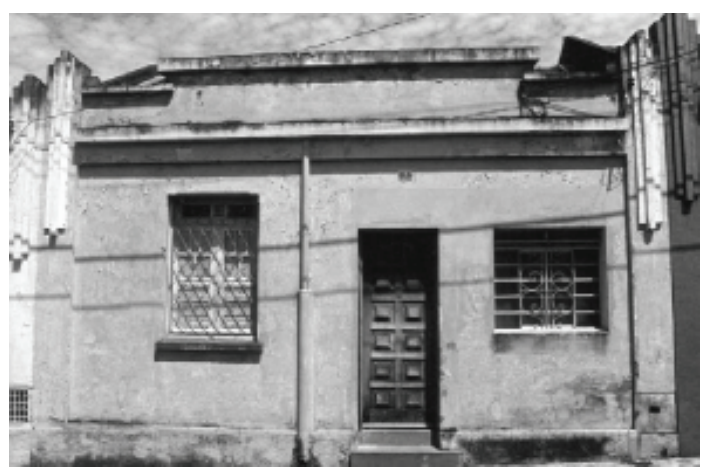

Piracicaba, São Paulo

Vila Boyes, erguida pela Indústria Boyes, 2001

Atendendo a preceitos higienistas e, às vezes, à intenção de diferenciar casas destinadas a técnicos especializados, casas geminadas duas a duas foram erguidas com freqüência em vilas operárias e núcleos fabris. 


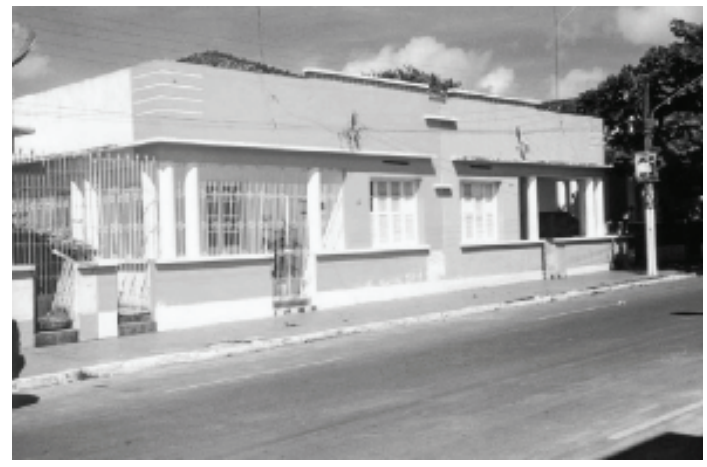

Goiana, Pernambuco

Casas para operários e para técnicos especializados, 2000

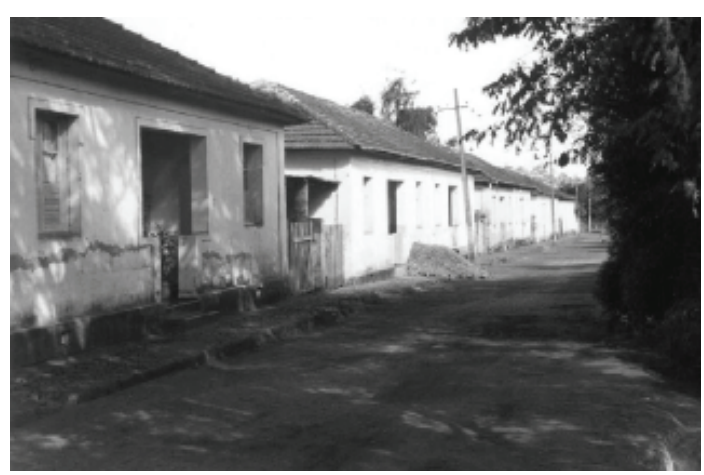

Itabirito, Minas Gerais

Casas pertencentes à Valadares Diesel Ltda., 1998

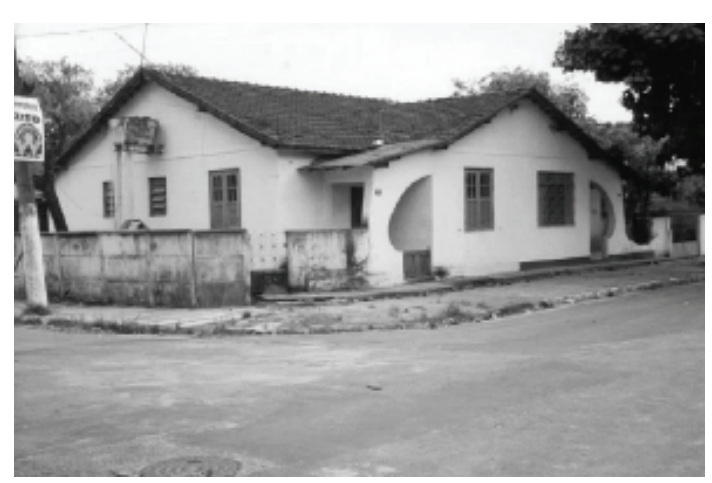

Duque de Caxias, Rio de Janeiro

Casas edificadas pela Fábrica Nacional de Motores, 1998

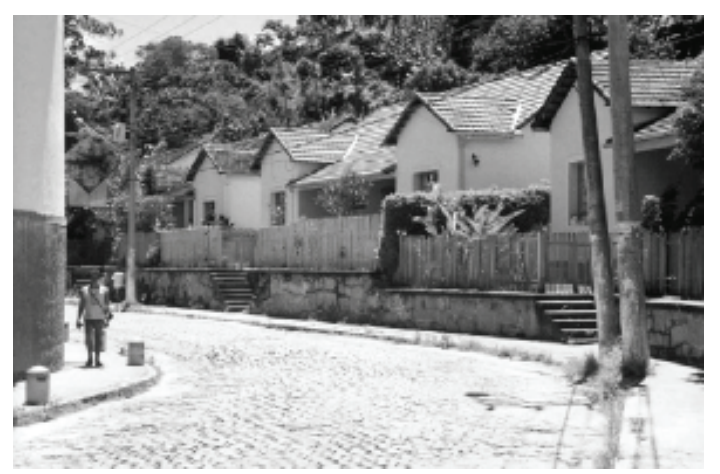

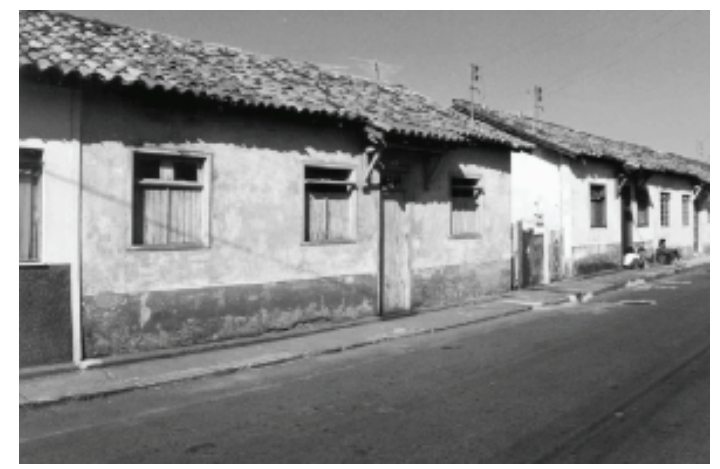

Sabará, Minas Gerais

Casas construídas pela Siderúrgica Belgo-Mineira, 1998

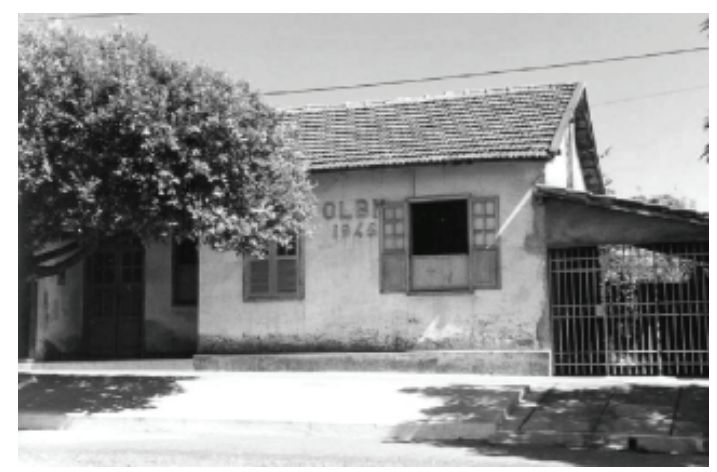

Curvelo, Minas Gerais

Casa construída pela Fábrica Maria Amália, 1998

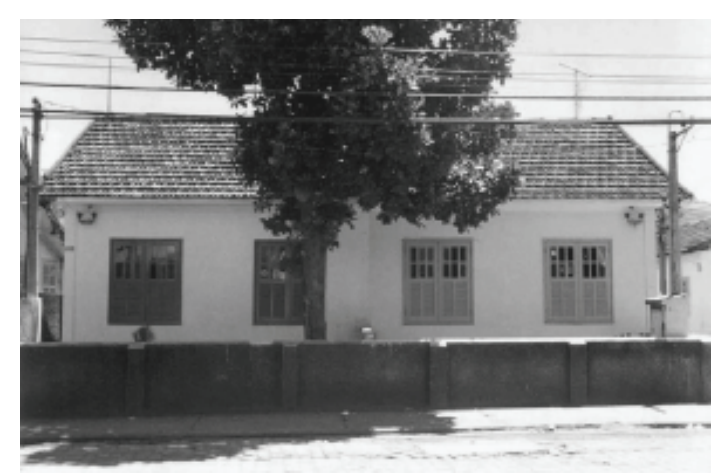

Barra Mansa, Rio de Janeiro

Casa erguida pela Siderúrgica Barra Mansa, 2002

Nova Friburgo, Rio de Janeiro

Casas erguidas pela Fábrica de

Filó S. A., 2002 


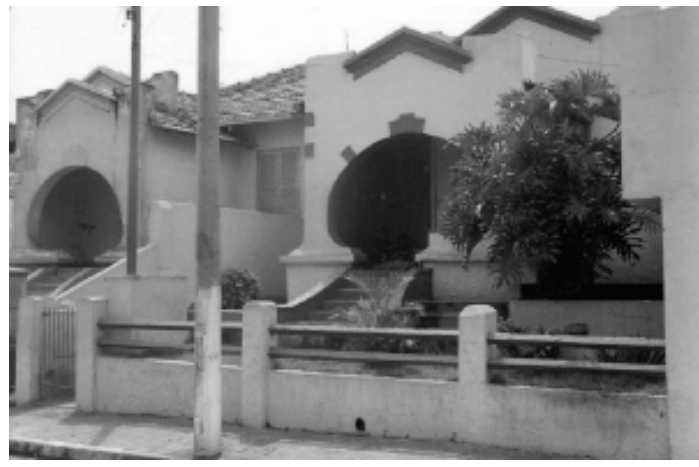

Alumínio, São Paulo

Casas edificadas pela Companhia

Brasileira de Alumínio, 2001

A partir da segunda metade dos anos 30, a construção de vilas e núcleos de empresas no Brasil passou por uma alteração importante, caracterizada pela crescente participação de urbanistas e arquitetos elaborando planos e projetos de construções para esses locais.

Marcos importantes, desse novo momento, foram o concurso para o plano de Monlevade (1934) e a proposta do arquiteto Attílio Corrêa Lima para Volta Redonda (1941). Um outro exemplo de núcleo fabril projetado por arquiteto é Harmonia, criado pela Fábrica de Papel e Celulose Klabin, no Paraná, cujo plano de urbanismo foi elaborado em 1943 pelo arquiteto Abelardo Caiubí.

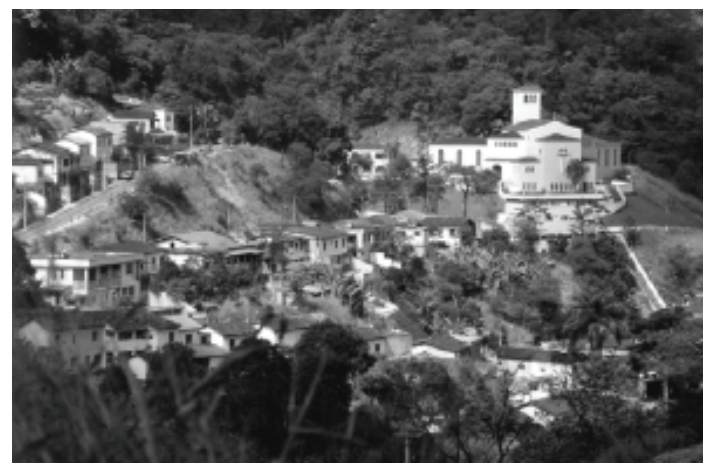

Monlevade, Minas Gerais

Núcleo fabril erguido pela Companhia Siderúrgica Belgo Mineira, 1998

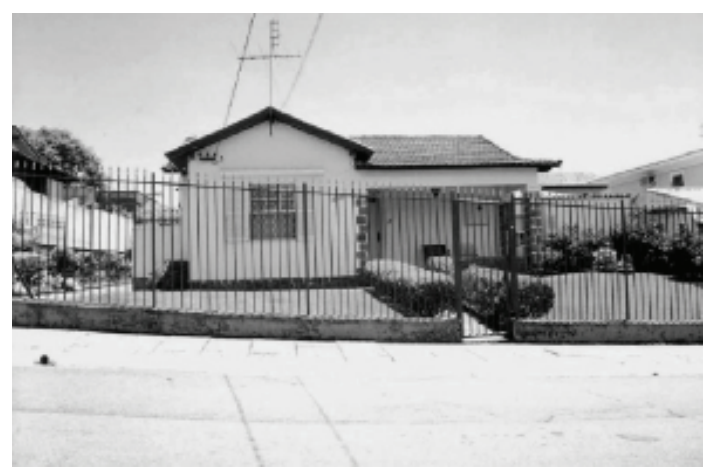

Volta Redonda, Rio de Janeiro

Casas, alojamento para solteiros e prédios de apartamentos construídos pela CSN, 2001

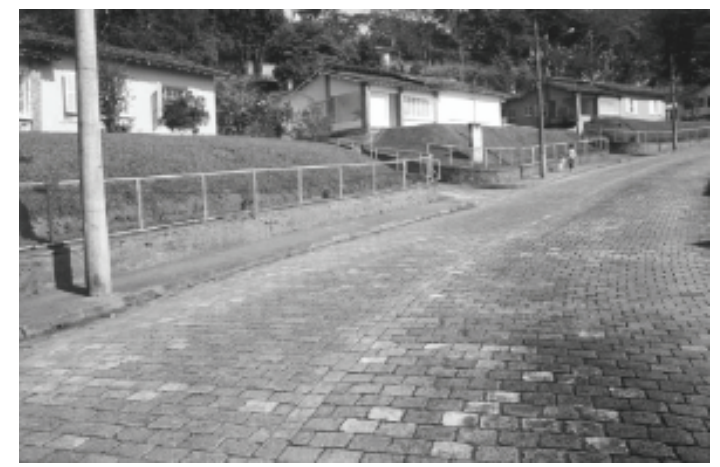

Monlevade, Minas Gerais

Núcleo fabril erguido pela Companhia Siderúrgica BelgoMineira, 1998

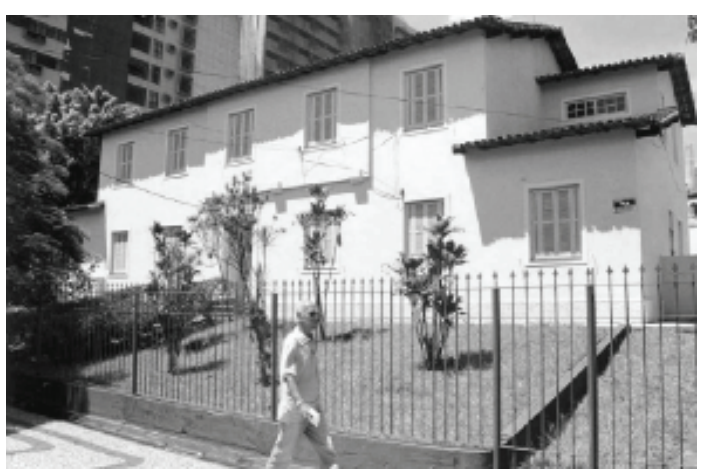

Volta Redonda, Rio de Janeiro

Casas, alojamento para solteiros e prédios de apartamentos construídos pela CSN, 2001 


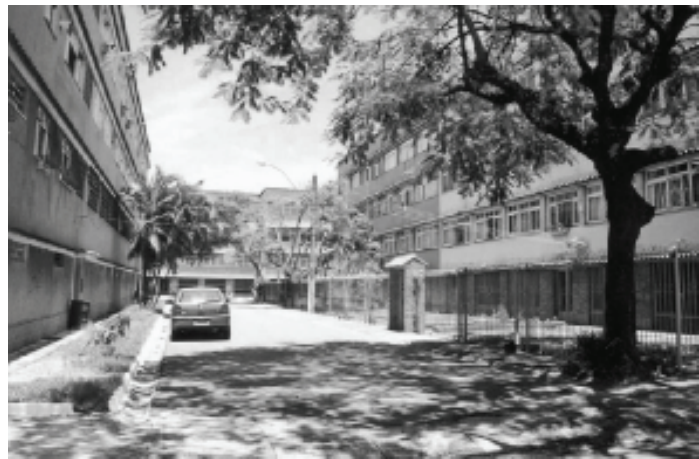

Volta Redonda, Rio de Janeiro - Casas, alojamento para solteiros e prédios de apartamentos construídos pela CSN, 2001

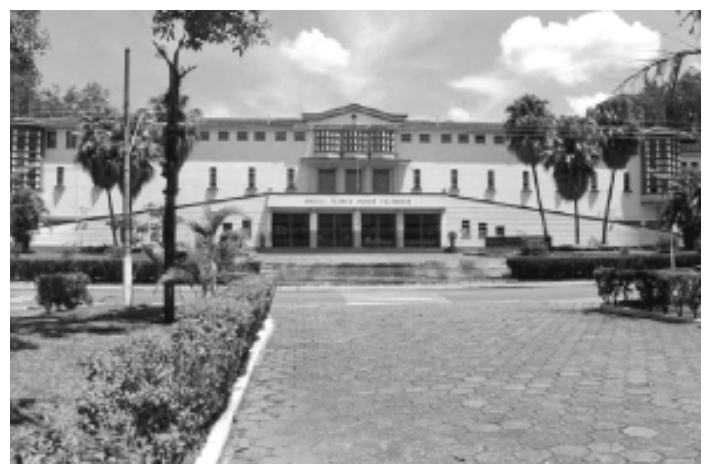

Volta Redonda, Rio de Janeiro

Igreja, escola técnica e cinema construídos pela CSN, 2001

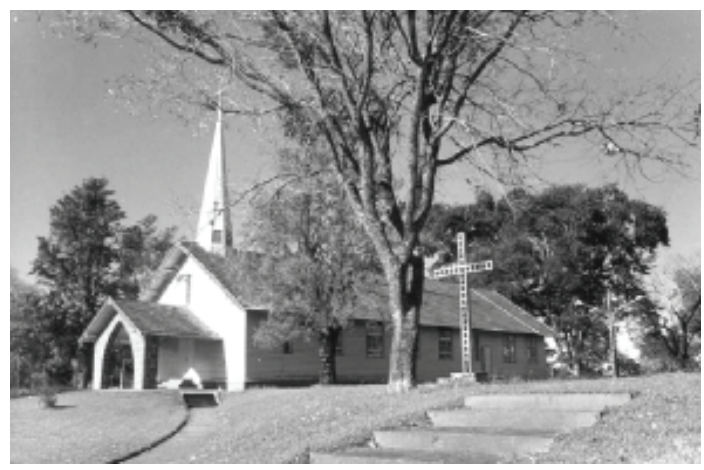

Telêmaco Borba, Paraná

Igreja em Harmonia, núcleo residencial criado pela Indústria Klabin de Papel e Celulose, 1996

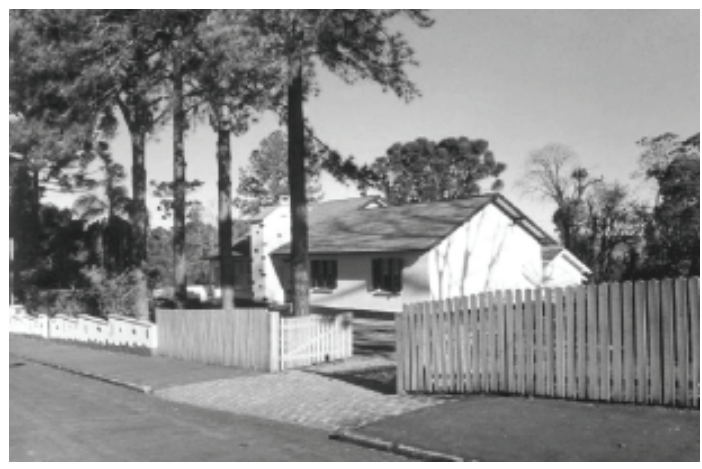

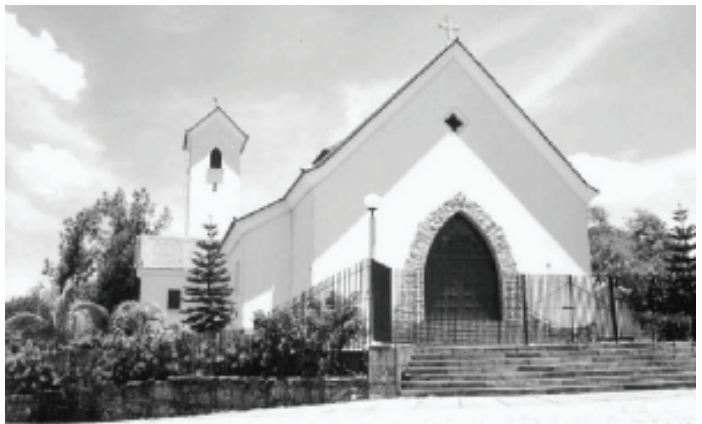

Volta Redonda, Rio de Janeiro

Igreja, escola técnica e cinema construídos pela CSN, 2001

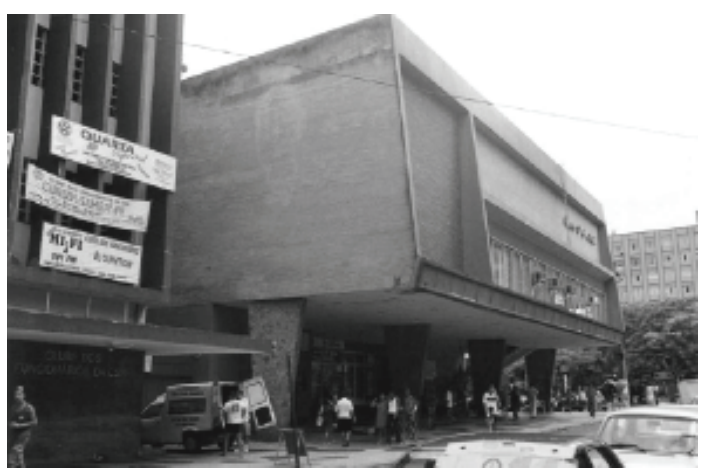

Volta Redonda, Rio de Janeiro

Igreja, escola técnica e cinema construídos pela CSN, 2001

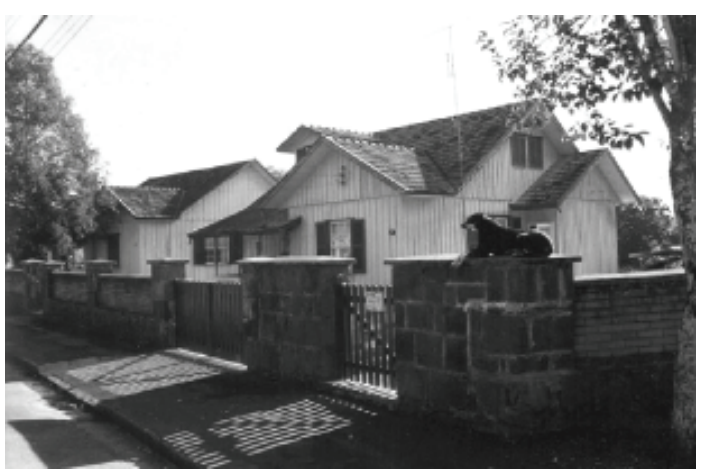

Telêmaco Borba, Paraná

Casas em Harmonia, núcleo residencial criado pela Indústria Klabin de Papel e Celulose, 1996

Telêmaco Borba, Paraná

Casas em Harmonia, núcleo residencial criado pela Indústria Klabin de Papel e Celulose, 1996 
Na década de 50, a tendência da concepção de planos para vilas e núcleos de empresas por urbanistas persiste, em projetos elaborados por alguns dos mais destacados arquitetos que atuaram no Brasil no século 20. Esse foi o caso do projeto do núcleo residencial realizado pelos arquitetos Jacques Pilon e Giancarlo Gasperini para a Fábrica Mecânica Pesada em 1956.

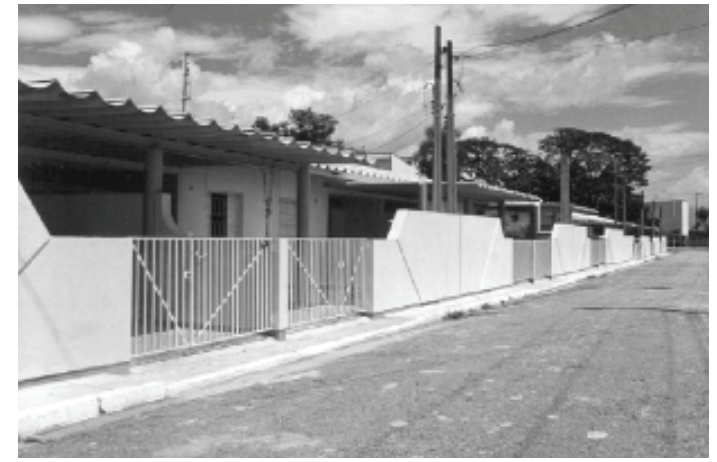

Taubaté, São Paulo -

Casas edificadas pela Fábrica Mecânica Pesada, 2001

\section{AS EXPERIÊNCIAS TARDIAS, I96I-I990}

A partir dos anos 60, verificou-se um claro declínio da prática de construção de moradias por empresas no Brasil, que, entretanto, não é interrompida.

Conjuntos de casas foram erguidos, entre outros, pela Aços Finos Piratini (década de 60), pela Ferteco Mineração S/A (1977), pela Piccadilly (entre meados da década de 70 a meados da década seguinte), pela Aracruz Celulose (1975), pela Açominas (década de 80) e pela Battistella Indústria e Comércio (1987).

A Votorantim - grupo que criou um número muito grande de moradias para seus empregados em vilas operárias e núcleos fabris, situados em diferentes estados do país - continuou a erguer conjuntos residenciais nesse período, pela Companhia Mineira de Metais (fim da década de 60), da Fábrica de Papel e Papelão Pedras Brancas (nas décadas de 70 e 80) e da Celpav (1990).

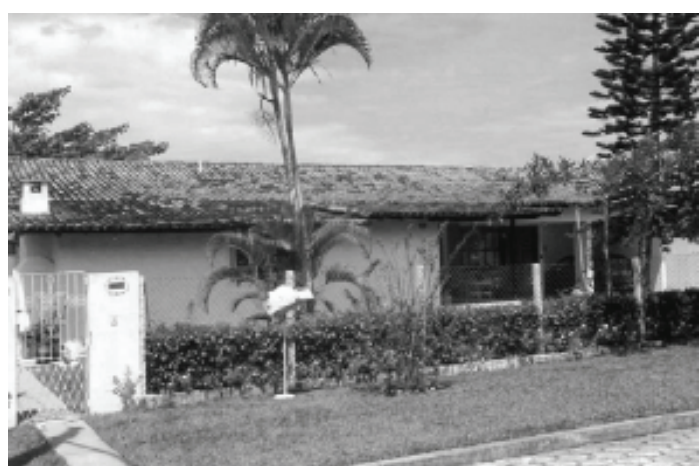

Aracruz, Espírito Santo

Coqueiral, núcleo residencial construído pela Aracruz Celulose S. A., 2002

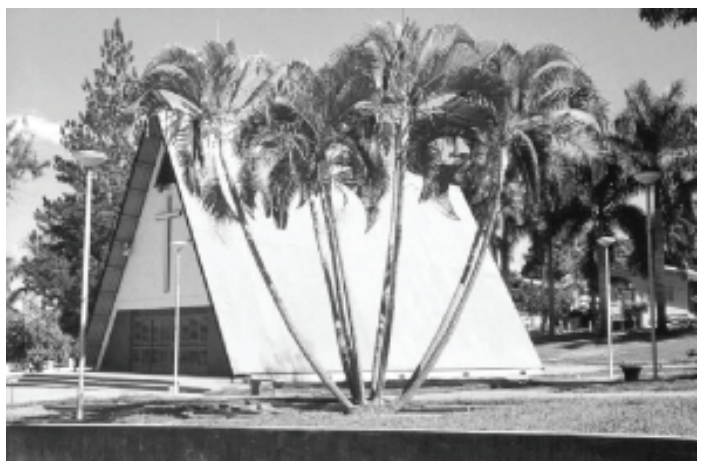

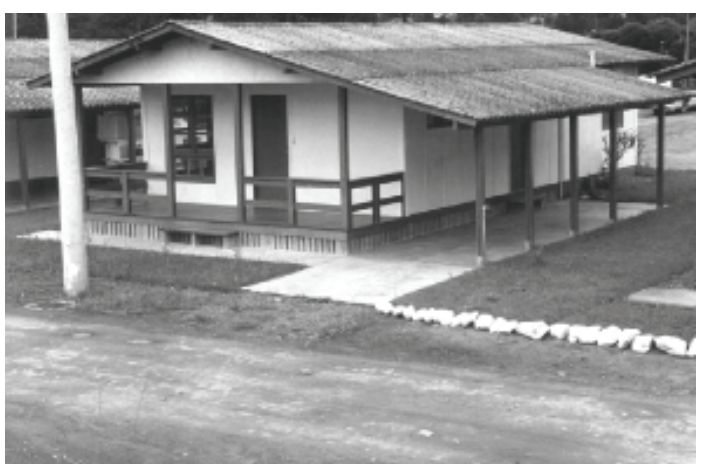

Rio Negrinho, Santa Catarina

Casa erguida pela Battistella Indústria e Comércio, 1996
Três Marias, Minas Gerais Igreja no núcleo residencial da Companhia Mineira de Metais, 1998 


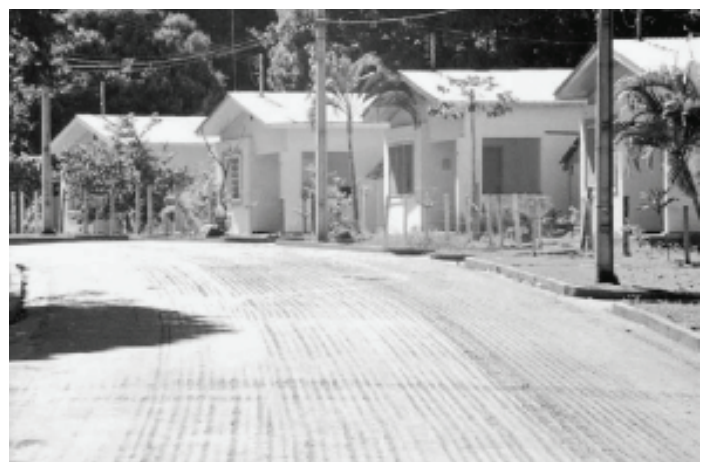

Três Marias, Minas Gerais

Casas no núcleo residencial da Companhia Mineira de Metais, 1998

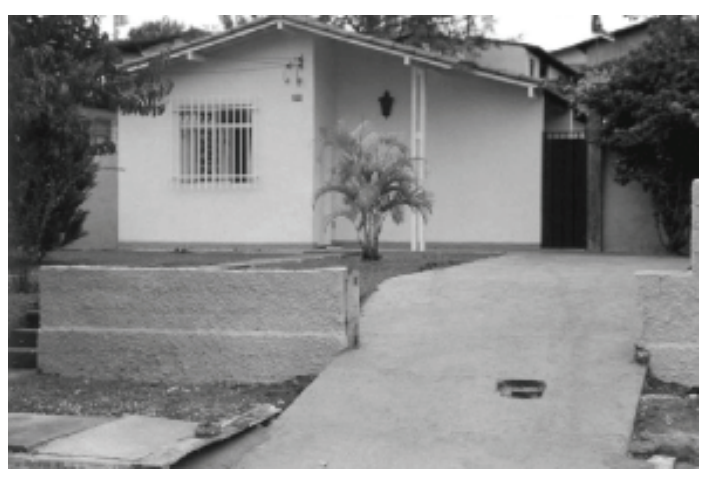

Ouro Branco, Minas Gerais

Casas erguidas pela Açominas, 1998

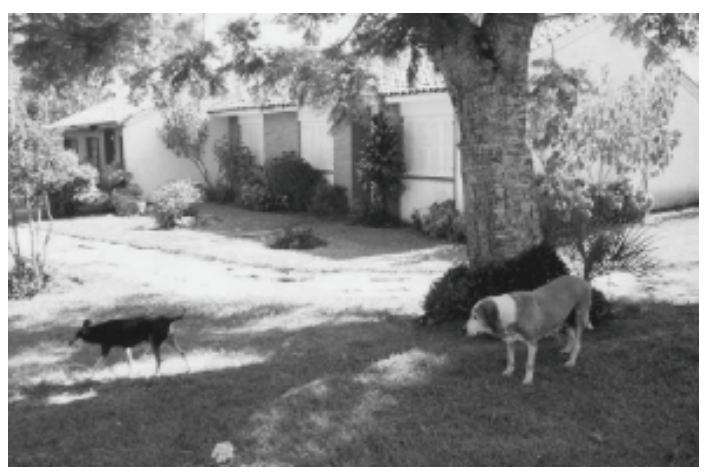

Charqueadas, Rio Grande do Sul

Vila Aços Finos Piratini, 1997

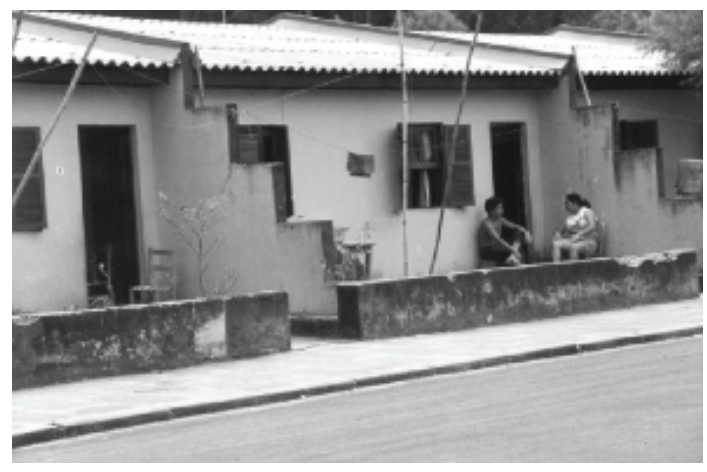

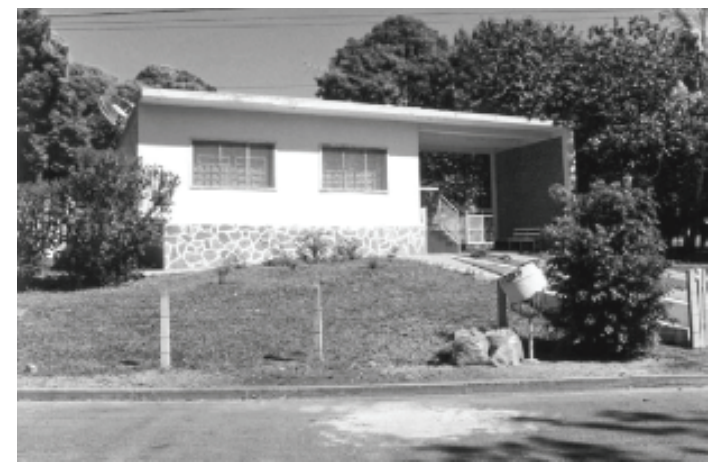

Três Marias, Minas Gerais

Casas no núcleo residencial da Companhia Mineira de Metais, 1998

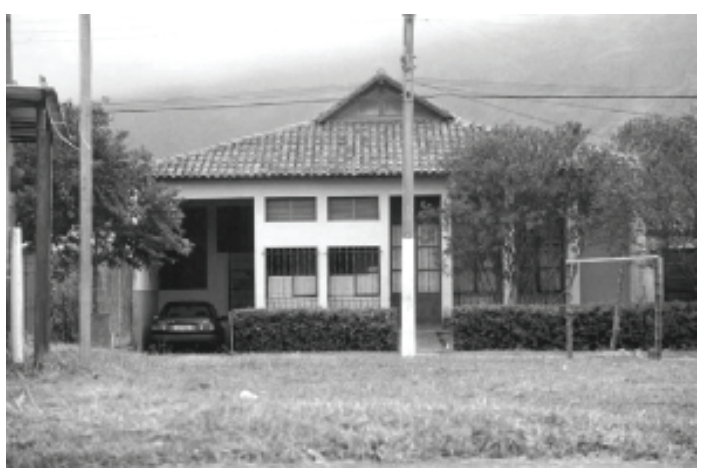

Ouro Branco, Minas Gerais

Casas erguidas pela Açominas, 1998

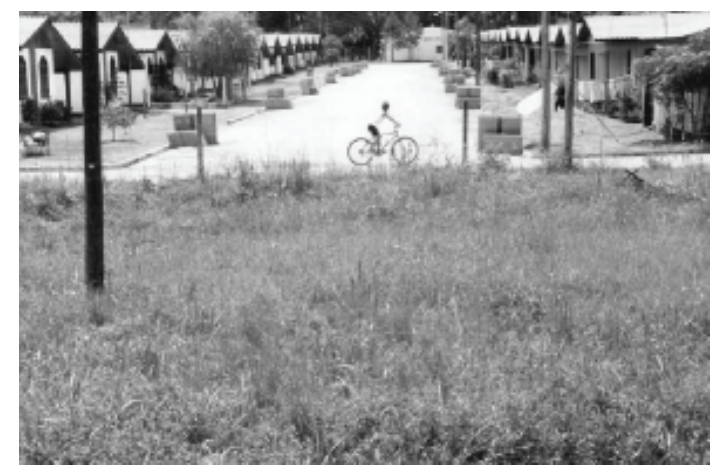

Igrejinha, Rio Grande do Sul

Vila operária da Fábrica Piccadilly, 1997

Igrejinha, Rio Grande do Sul

Vila operária da Fábrica Piccadilly, 1997 


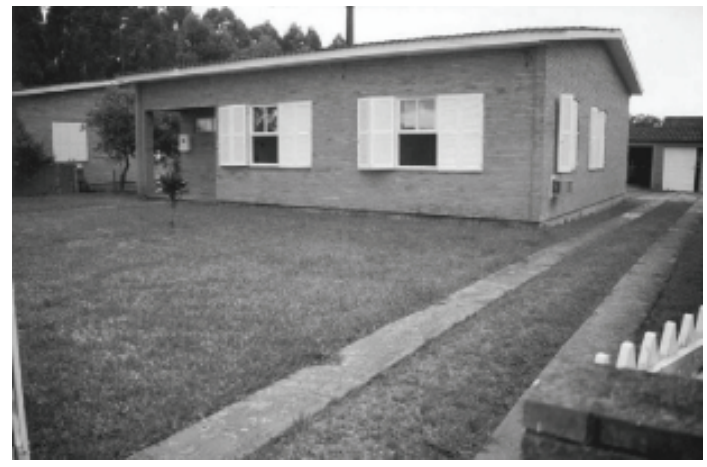

Guaíba, Rio Grande do Sul

Vila da Fábrica de Papel e Papelão Pedras Brancas, 1997

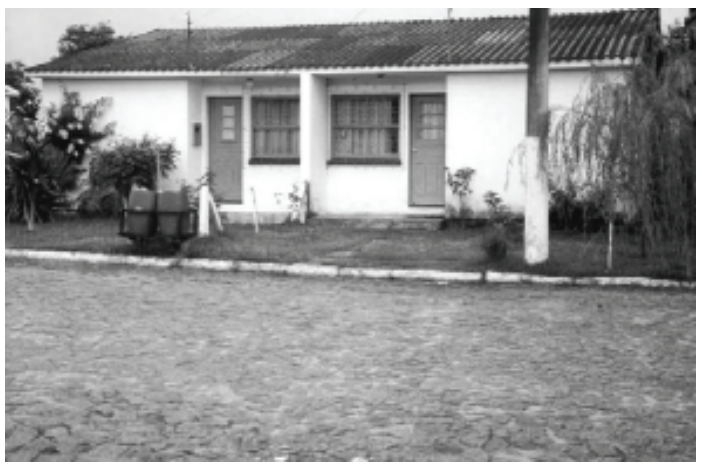

Guaíba, Rio Grande do Sul

Vila da Fábrica de Papel e Papelão Pedras Brancas, 1997

\section{O DESMONTE}

Recuperar a história das vilas operárias e os núcleos residenciais criados por fábricas e por empresas de mineração no Brasil nos séculos 19 e 20 é, também, entender o sentido de suas rápidas transformações em termos de configuração espacial e de uso. A trajetória de muitos desses lugares foi um processo contínuo de construção, ampliação e transformações.

Um dos momentos desse processo de transformação é seu desmonte. Motivadas por causas diversas, empresas começaram a desfazer-se de suas casas e equipamentos de uso coletivo em diferentes estados do Brasil, fazendo com que as vilas e núcleos residenciais que criaram se encontrem, na maioria dos casos, descaracterizados ou demolidos.

Há muitos casos nos quais não ocorre uma destruição material das construções, mas uma transformação, que pode significar uma total desfiguração.

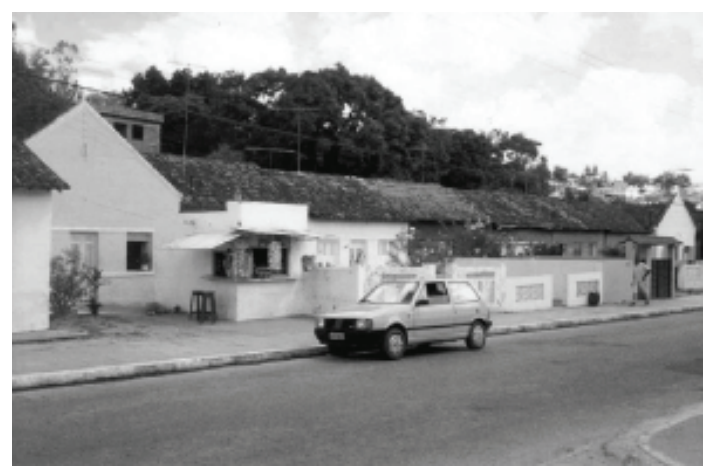

Moreno, Pernambuco -

Casas construídas pela Societé Cotonniére BelgeBrésilienne, 1995

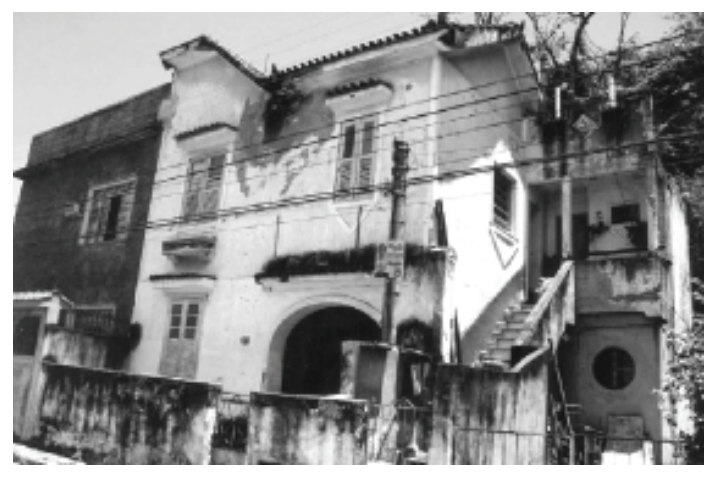

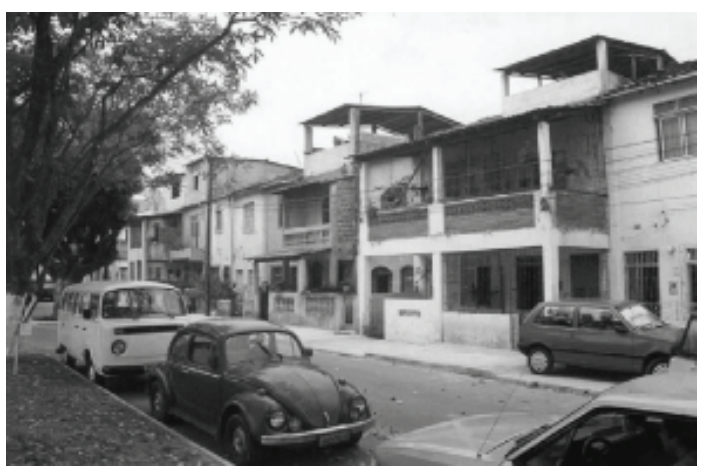

Salvador, Bahia -

Vila Boa Viagem, criada pelo Empório Industrial do Norte, 1997

Niterói, Rio de Janeiro

Vila operária da Companhia

Commercio e Navegação, 2004 


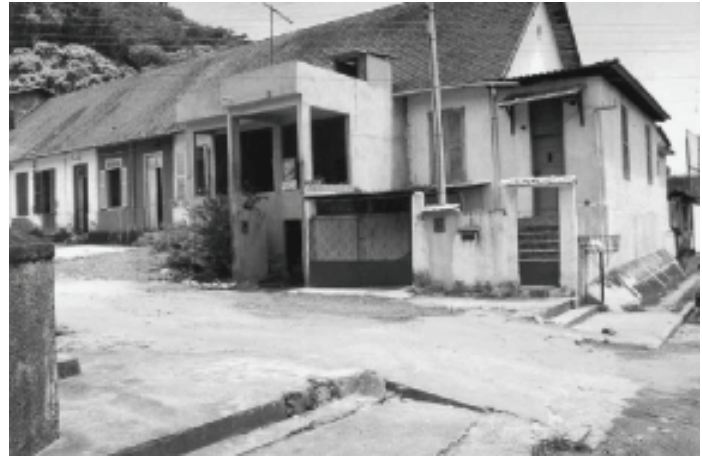

Magé, Rio de Janeiro

Vila operária da Fábrica Esther, 1998

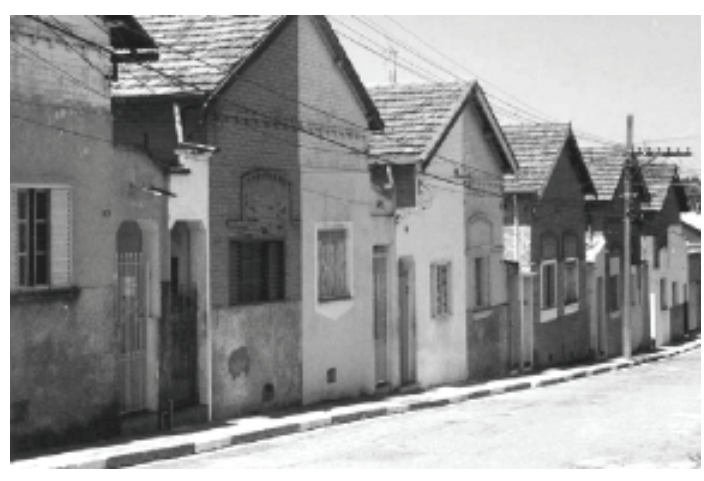

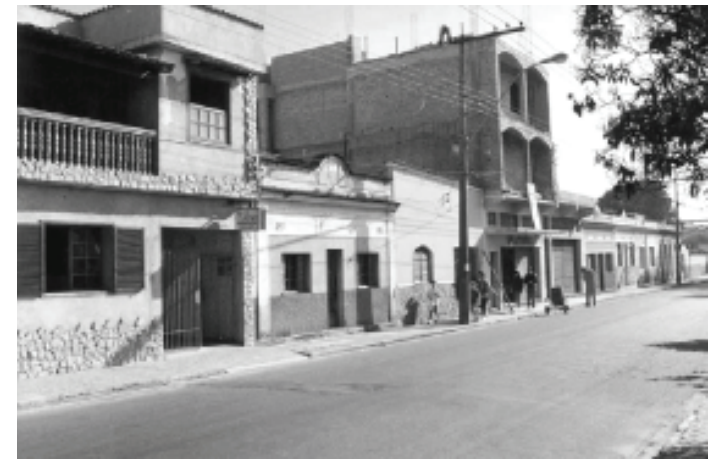

São João del Rei, Minas Gerais

Casas construídas pela Companhia Têxtil São Joanense, 1998

Sorocaba, São Paulo

Casas erguidas pela

Companhia de Fiação e

Tecidos Santa Maria, 2001

Em muitos casos o desmonte pode significar a total demolição e desaparecimento das construções após algumas décadas de existência.

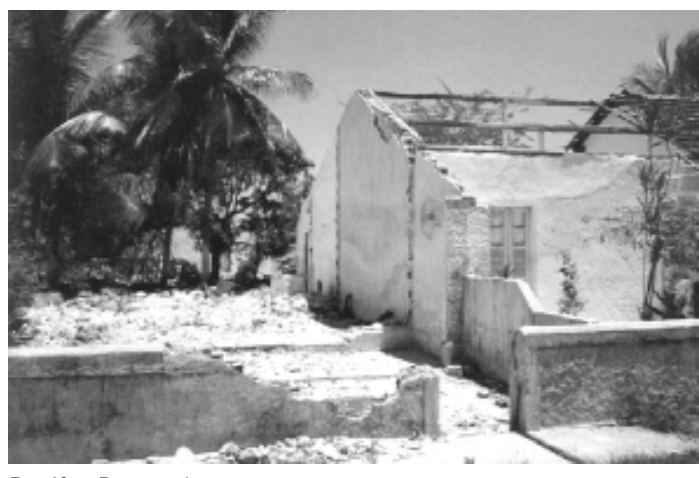

Recife, Pernambuco

Casas sendo demolidas na Vila Iolanda criada pela Fábrica Iolanda, 1996

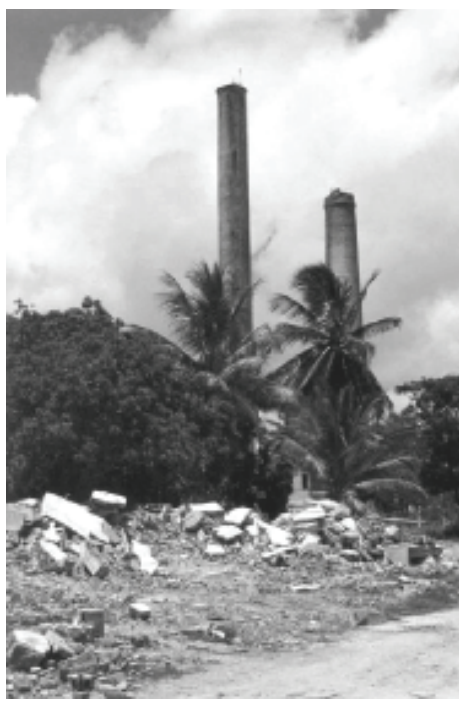

Paulista, Pernambuco Aspectos da Vila Poty, da Fábrica de Cimento Poty, do Grupo Votorantim 1996 


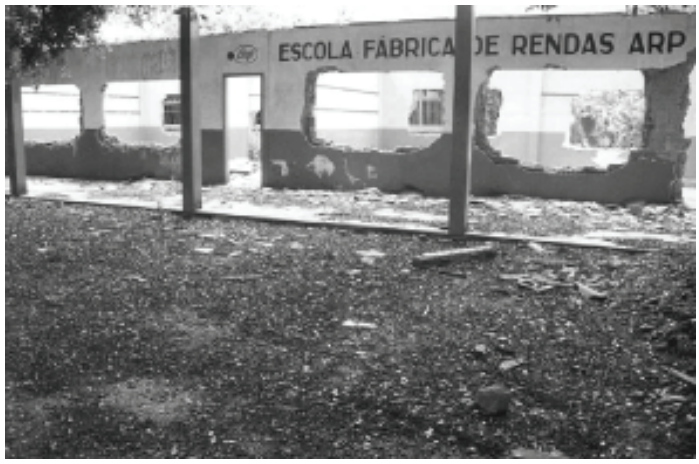

Nova Friburgo, Rio de Janeiro

Escola da vila operária da Fábrica de Rendas Arp., 1998

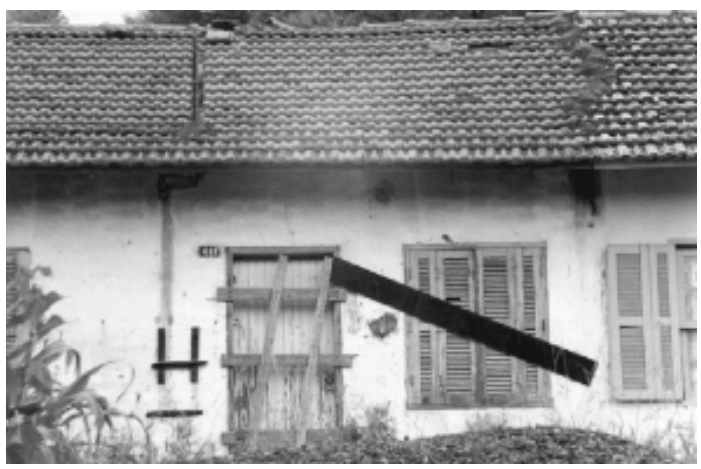

Votorantim, São Paulo

Demolições na Vila Santa Helena, criada pela Fábrica de Cimento Votorantim, 2003

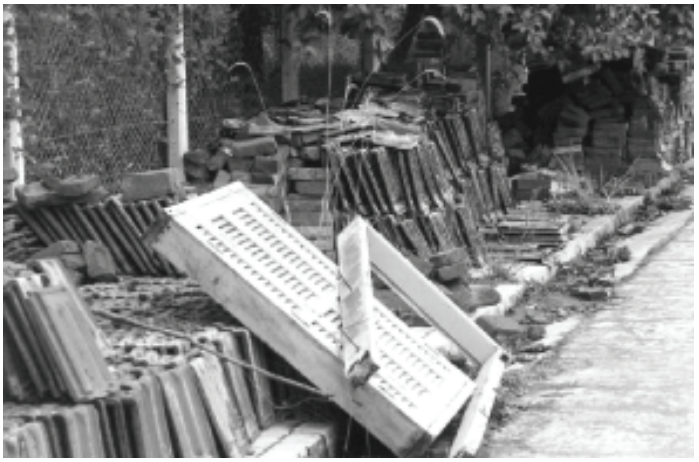

Votorantim, São Paulo

Demolições na Vila Santa Helena, criada pela Fábrica de Cimento Votorantim, 2003

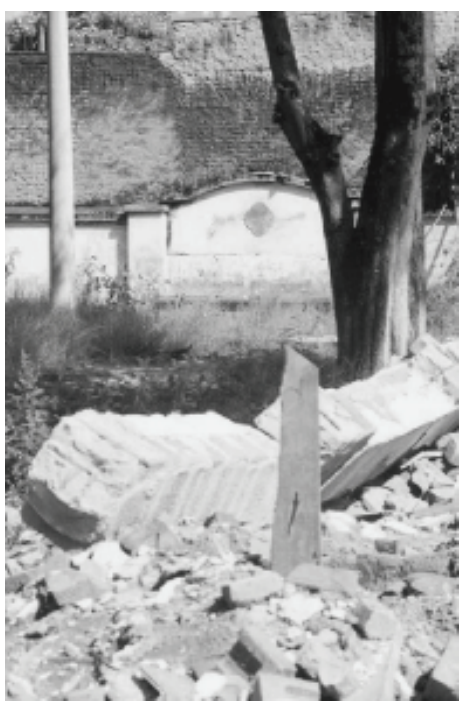

São José dos Campos, São Paulo Vila da Tecelagem Parahyba, 2001

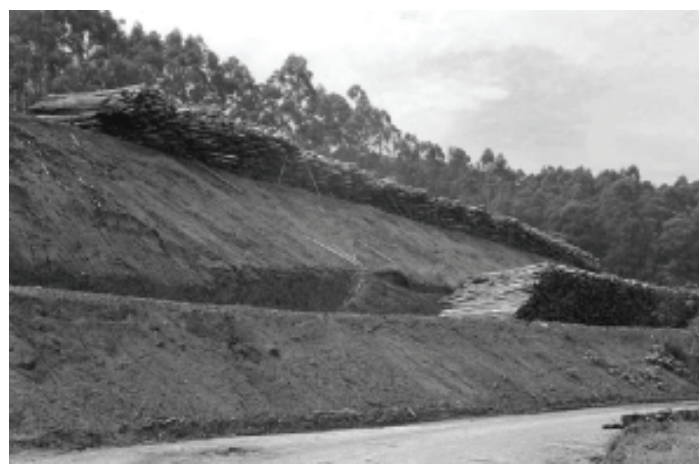

Jacareí, São Paulo

Depósito de madeira em local onde existiram casas da Indústria de Papel Simão, 2001

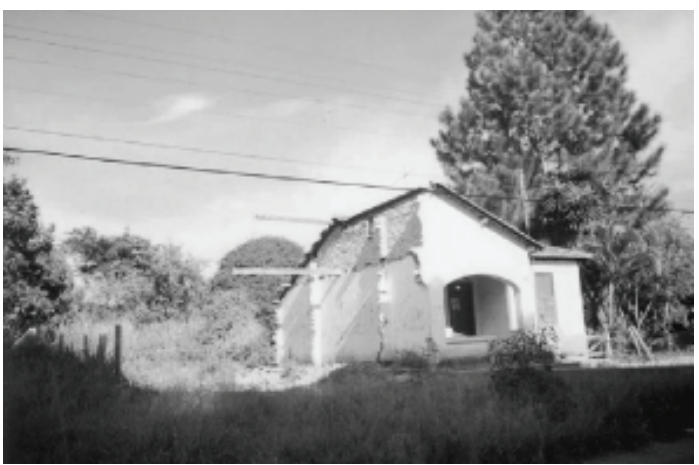

Pindamonhangaba, São Paulo

Demolições no núcleo residencial criado pela Companhia Agrícola e Industrial Cícero Prado, 2001 


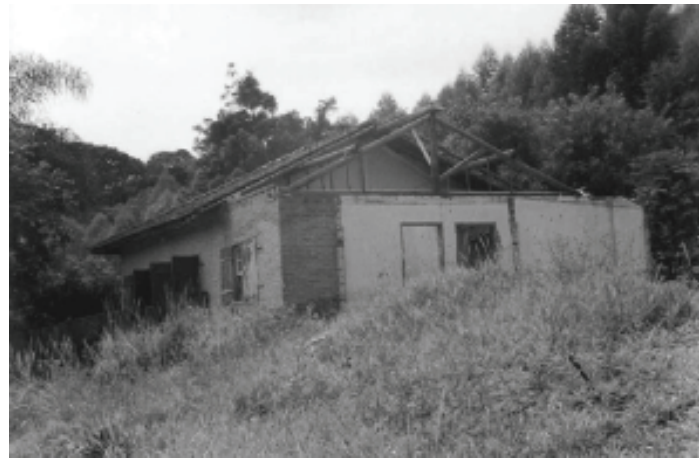

Caieiras, São Paulo

Demolições no núcleo residencial criado pela Companhia Melhoramentos S.A., 2002

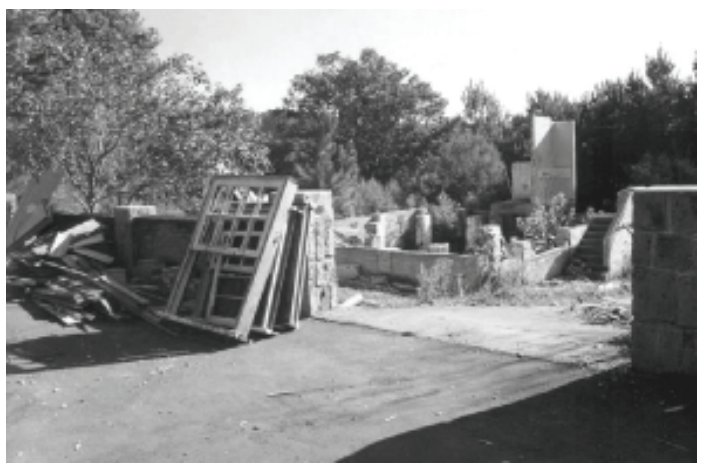

Telêmaco Borba, Paraná

Casa sendo desmontada em Harmonia, núcleo residencial criado pela Indústria Klabin de Papel e Celulose, 1996

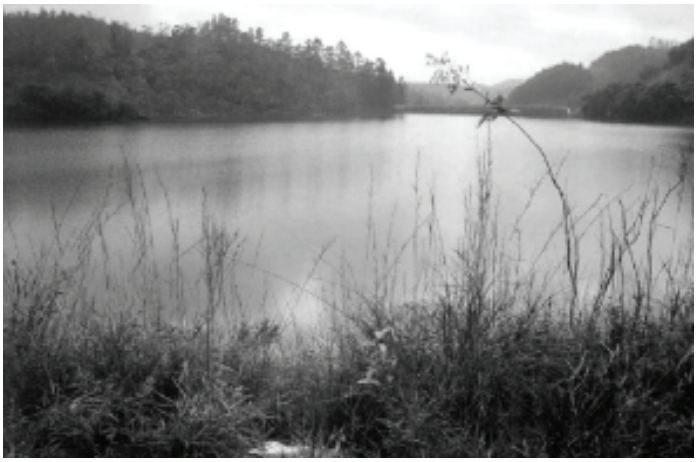

Itabira, Minas Gerais

Açude criado no local onde existiu a Companhia Fabril Pedreira e seu núcleo residencial, 1998

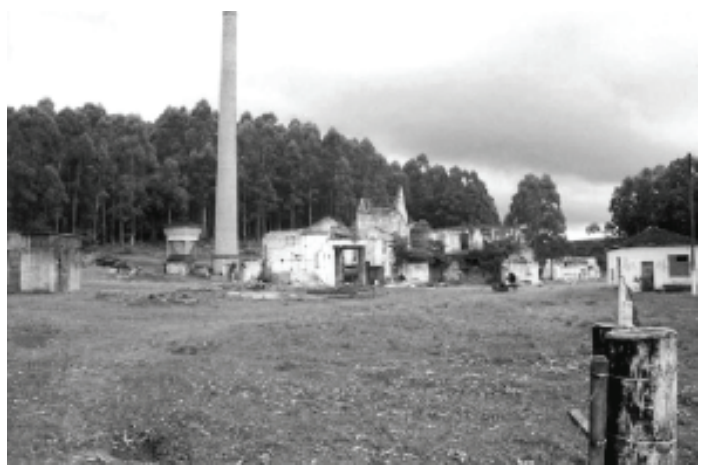

Guaíba, Rio Grande do Sul

Ruínas da fábrica e local onde existiu o núcleo fabril criado pela Companhia Fábrica de Papel e da Papelão, em Bom Retiro, 1996

Fotos: Philip Gunn

Telma de Barros Correia

Professora Associada e pesquisadora do Departamento de Arquitetura e Urbanismo da EESC-USP.

Khaled Ghoubar

Professor Livre-Docente do Departamento de Tecnologia da Arquitetura da FAUUSP e pesquisador do NAP/PLAC - USP.

Yvonne Mautner

Professora Doutora da Pós-graduação FAUUSP e pesquisadora do NAP/PLAC - USP. 